1 THE EXTINCTION AND SURVIVAL OF SHARKS ACROSS THE END-CRETACEOUS

\title{
2 MASS EXTINCTION
}

3

4 Mohamad Bazzi $^{1}{ }^{*}$, Nicolás E. Campione ${ }^{2}$, Per E. Ahlberg ${ }^{1}$, Henning Blom $^{1}$, Benjamin P.

$5 \operatorname{Kear}^{3 *}$

6

$7 \quad{ }^{1}$ Subdepartment of Evolution and Development, Department of Organismal Biology, Uppsala

8 University, Norbyvägen 18A, SE-752 36 Uppsala, Sweden.

$9 \quad{ }^{2}$ Palaeoscience Research Centre, School of Environmental and Rural Science, University of

10 New England, Armidale 2351, New South Wales, Australia.

$11{ }^{3}$ Museum of Evolution, Uppsala University, Norbyvägen 16, SE-752 36 Uppsala, Sweden.

12

13

14 *Corresponding authors: mohamad.bazzi@ebc.uu.se; benjamin.kear@em.uu.se 
bioRxiv preprint doi: https://doi.org/10.1101/2021.01.20.427414; this version posted January 20, 2021. The copyright holder for this preprint (which was not certified by peer review) is the author/funder, who has granted bioRxiv a license to display the preprint in perpetuity. It is made available under aCC-BY 4.0 International license.

15 Keywords: Selachimorpha, Macroevolution, Extinction recovery dynamics, Geometric

16 Morphometrics, Morphospace-Disparity Framework 
17 Abstract: Sharks (Selachimorpha) are iconic marine predators that have survived multiple mass extinctions over geologic time. Their fossil record is represented by an abundance of teeth, which traditionally formed the basis for reconstructing large-scale diversity changes among different selachimorph clades. By contrast, corresponding patterns in shark ecology, as measured through morphological disparity, have received comparatively limited analytical attention. Here, we use a geometric morphometric approach to comprehensively examine the dental morphology of multiple shark lineages traversing the catastrophic end-Cretaceous mass extinction — this event terminated the Mesozoic Era 66 million years ago. Our results show that selachimorphs maintained virtually static levels of dental disparity in most of their constituent clades during the Cretaceous/Paleogene transition. Nevertheless, selective extinctions did impact on apex predator lineages characterized by triangular blade-like teeth, and in particular, lamniforms including the dominant Cretaceous anacoracids. Other groups, such as, triakid carcharhiniforms, squalids, and hexanchids, were seemingly unaffected. Finally, while some lamniform lineages experienced morphological depletion, others underwent a post-extinction disparity increase, especially odontaspidids, which are typified by narrow-cusped teeth adapted for feeding on fishes. This disparity shift coincides with the early Paleogene radiation of teleosts, a possible prey source, as well as the geographic relocation of shark disparity 'hotspots', perhaps indicating a regionally disjunct pattern of extinction recovery. Ultimately, our study reveals a complex morphological response to the end-Cretaceous mass extinction event, the dynamics of which we are only just beginning to understand. 


\section{INTRODUCTION}

39 Fossils provide the only direct evidence for the interplay between organisms and their environments over vast evolutionary timescales [1-3]. They are, therefore, crucial for

41 exploring the drivers of biodiversity and ecosystem change in the past, with potential insights on the origin of present-day ecosystems [3]. However, the analytical challenge is to discern a genuine biological signal relative to geologic, taphonomic, sampling, and philosophical biases

44 [4-7]. While these may be impossible to overcome in entirety, the fossil records of some widely distributed and chronostratigraphically extended clades offer reasonable proxies for modelling macroevolutionary processes through deep time.

47 Sharks constitute just such a 'model group' because their dental remains are abundant in

48 Mesozoic and Cenozoic marine deposits — a timeframe that covers 250 million years (Ma)

$49[8,9]$. Extant shark species are also ecologically ubiquitous, encompassing a spectrum of macrophagous to microphagous predators that account for nearly half (42\%) of all the

51 currently documented chondrichthyan biodiversity ( $n=1193$ species) [10,11]. Nevertheless,

52 after nearly 200 years of scientific research [9], the various biological and environmental

53 factors that shaped shark evolution in the distant past remain obscure. In particular, their

54 capacity to survive past mass extinctions is relevant for understanding the dramatic decline of

55 shark populations observed in modern oceans [11-15].

56 The end-Cretaceous mass extinction ( 66 Ma), which marks Cretaceous/Paleogene (K/Pg)

57 chronostratigraphic boundary, is especially pertinent because it profoundly disrupted marine

58 ecosystems, but has had disputed implications for shark species diversity and morphological

59 disparity. Indeed, contrasting interpretations have advocated either limited [16], or complex

60 interrelationships between various biotic and abiotic drivers influencing shark evolution from

61 before, during, and after the K/Pg mass extinction event [17-20]. Here, we attempt to resolve 
62 the extinction dynamics and inferred mechanisms of sharks via a comprehensive assessment

63 of their dental morphological disparity across the end-Cretaceous mass extinction. Our

64 approach expands on previous studies that have targeted either geographically localized

$65[21,22]$, or clade-specific [20] assemblages. We use a dataset of 1,239 fossil shark teeth,

66 representing nine major selachimorph clades sampled at global and regional scales. These

67 groups include: the Galeomorphii orders Carcharhiniformes, Heterodontiformes,

68 Lamniformes, Orectolobiformes; Squalomorphii orders Echinorhiniformes, Hexanchiformes,

69 Squaliformes, Squatiniformes; and the extinct [ $\dagger$ ] Synechodontiformes. Our geometric

70 morphometric analysis compares changing patterns of dental disparity and morphospace

71 across a constrained 27.6-million-year interval spanning the Campanian and Maastrichtian

72 ages of the Late Cretaceous (83.6-66 Ma), to the Danian, Selandian, and Thanetian ages

73 (=Paleocene epoch) of the early Paleogene (66-56 Ma). Using this new dataset, we test the

74 following hypotheses via their associated predictions. 1) Long-term shifts in Earth Systems in

75 the twilight of the Mesozoic, including major global regressions during the Maastrichtian,

76 saw to a loss of marine habitats $[22,23]$. We, therefore, predict that shark diversity and

77 disparity were in decline prior to the mass extinction event. 2) The end-Cretaceous was a

78 devastating period for sharks, as hypothesized by major losses in the diversity of species,

79 genera, and families $[17,18]$. Such losses, especially at higher taxonomic ranks, suggest

80 concomitant losses in ecological diversity, which should be expressed by notable disparity

81 decreases at the Boundary. 3) Previous studies hypothesized a non-random, selective

82 extinction of sharks, in particular against pelagic large-bodied pelagic apex predators and

83 shallow-water carpet shark [17,20,24]. As a result, we predict that the extinction event was

84 biasedly more catastrophic towards specific morphotypes (e.g., 'cutting-type' dentitions),

85 while others remained largely unaffected. 4) The end-Cetaceous extinction was a global event

86 and, as such, we predict that all major late Mesozoic ocean habitats were consistently 
87 affected, leading to similar disparity profiles at both regional and global scales. 5) The aftermath of the extinction saw to a major radiation of teleost fish [16], a potentially important food source for the surviving sharks. As such, we predict a Paleocene proliferation of morphologies associated with bony-fish diets, such as elongate, thin teeth of the 'piercing'

91 and 'tearing-type' designs.

\section{MATERIALS AND METHODS}

Dataset assembly

94 Our dataset of 1,239 teeth includes photographs or images of fossil selachimorph teeth taken

95 from first-hand observations or compiled from the literature (Appendix S1; S1 Fig and S1 and S2 Table). Following recommended best-practices $[20,25,26]$, our raw image data was screened to only include tooth specimens with complete crowns and of adequate resolution, so as to unambiguously determine the position of the root-crown junction. Our global coverage includes sharks from nearly all taxonomic orders (S1 and S2A Fig), with the exception of Pristiophoriformes (Sawsharks), which have a notoriously sparse fossil record $[8,27]$. We also elevated Echinorhinidae to Echinorhiniformes [28-30], and employed a sensitivity analysis to test the morphospace occupation and disparity effects of $\dagger$ Synechodontiformes, which are classified as either a clade of Galeomorphii, or a

104 neoselachian sister lineage (S2A Fig) [31-34]. Finally, all images were standardised so that

105 the tooth apex was directed to the left and were generally digitized in the preferred labial aspect, unless only a lingual view was figured (S3 Fig). The equivalency of labial and lingual

107 views was demonstrated in [20] but we nonetheless verify it again here, through the use of 108 ordinary least-squares linear models and a sub-sample of the data for which both labial and 109 lingual views were digitized. 
110 Our dataset was time-binned across all five geochronological ages constituting the immediate

111 K/Pg interval: Campanian + Maastrichtian/Danian + Selandian + Thanetian. However, we

112 also implemented an alternative four-age time-binning scheme that pooled temporally

113 ambiguous specimens assigned to the Danian + Selandian (S3 and S4 Table). In addition, we

114 carried out analyses using a subsample of the dataset $(\mathrm{N}=829)$ for which sub-ages (early,

115 middle, and late) of the Campanian, Maastrichtian, and Danian could be defined (S5 Table).

116 Global taxonomic richness (henceforth referred to as just diversity) at genus-level and

117 morphological disparity were plotted against the mean Ma values taken from the International

118 Chronostratigraphic Chart v2020/03 [35].

119 Acquisition of geometric shape data

120 Landmark-based geometric morphometrics quantifies biological shapes as a series of 121 evolutionary homologous points in Cartesian space [25,26,36-41]. In sharks, however, the 122 evolutionary homology $[37,42]$ between landmarks cannot be assumed due the inherent 123 morphological variability of shark teeth (e.g., the location and number of cusplets). As a 124 result, the landmark types and placements are argued on the basis of topological homology $125[40]$.

126 Landmark digitization was carried out in tpsDig2 v. 2.31 [43] with resampling to a standard 127 number of equidistant semilandmarks carried out using customized code in $R$ v. 3.6.3 [44].

128 The resulting landmarking scheme comprise two open curves defined by semilandmarks and 129 anchored by three fixed landmarks: two Type 1 landmarks delimited the mesial and distal 130 crown-root junctions and one Type 2 landmark associated with the tooth apex (sensu [42];

131 S2B Fig and S6 Table). To identify the desired number of semilandmarks (k), the mesial and 132 distal curves were resampled seven times to increasing numbers of equally spaced 133 semilandmarks: $\mathrm{k}=40,60,80,100,120,140$, and 160. Qualitative observations (S4 and S5 
134 Fig) found that $\mathrm{k}=160$ best-captured tooth shape complexity (e.g., adequate shape coverage

135 of hexanchiforms) via distal and mesial curves of 78 and 79 sliding semilandmarks,

136 respectively. At this time, tooth serrations were not digitized due to image resolution, but we

137 acknowledge that they are functionally important [45].

138 Finally, to screen for possible digitization errors, we extracted a random sub-sample of 30

139 images (S7 Table) and used a one-way ANOVA to calculate the intra-class correlation

140 coefficient $(R)[25,46,47]$ (also see Supplementary text). We also ran a two-block partial

141 least-squares (2B-PLS) analysis to infer covariation between the datasets. Other exploratory

142 procedures performed as part of assessing measurement error include: 1) a manual survey of

143 digitized images to confirm accurate landmark placement and 2) screening for outliers. The

144 latter was performed visually, via observation of ordinated shape-space and associated thin-

145 plate spline (TPS) deformation grids and analytically, through an outlier search function,

146 plotOutliers, in the geomorph package geomorph v. 3.3.1 [48].

Morphometric analysis

148 To standardize digitized specimens to unit size, position, and rotation, we use a generalized

149 Procrustes analysis (GPA) [49,50] that minimizes the bending energies to optimize the

150 positions of the sliding semilandmarks [50,51]. Because large numbers of sliding

151 semilandmarks can impinge on GPA to reach proper convergence [25,37], we varied the

152 iteration frequency by arbitrarily increasing the max.iter argument in gpagan to compare

153 convergence criteria Q-values (= Procrustes sum of squares) and then inspected the resulting

154 consensus shape configurations (S6 Fig and S8 Table).

155 The aligned Procrustes coordinates were ordinated via a principal components analysis (PCA)

156 based on the singular value decomposition of the variance-covariance matrix. Shape variation

157 was depicted as both TPS deformation grids and deformation isolines to generate a 
158 concentration 'heat map' [52]. Ordinated space was visualised via back-transformation

159 [53,54]. All analyses were carried out in $R$ v. 3.6.3 [44] with the geomorph v. 3.3.1 [48] and $R R P P$ v. 0.6.2 [55] packages; visualization used the ggplot2 package [56]. All data and $R$

161 scripts are available from Data Dryad.

\section{Temporal analyses of morphospace}

163 Ordinated morphospace was categorized as time-bin boxplots that incorporated the arithmetic corresponded to the region of maximum frequency calculated as:

$$
M o_{\text {shape }_{j}}=\hat{\mu}_{p}+M o_{C_{j}} \times \Gamma_{j}
$$

170 shape configuration of the whole sample; $M o_{C_{j}}$ is the mode of the $j$ th PC axis; and, $\Gamma_{j}$ is the

171 rotation matrix corresponding to the jth PC. $M o_{\text {shape }_{j}}, \hat{\mu}_{p}$ and $\Gamma_{j}$ take the form of $\mathrm{k} \times \mathrm{m}$

172 matrices and were plotted as TPS deformation grids; $\mathrm{k}$ is the number of landmarks and $\mathrm{m}$ is

173 the dimensions, in our case 2.

174 Non-normal distributions were assessed using a Henze-Zirkler's test [57] for multivariate

175 normality $(H Z=4956, p=0)$ (S7 Fig). Statistical comparisons between time-bins used a non-

176 parametric Procrustes analysis of variance (PAV) implemented in the RRPP package [55].

\section{Temporal analyses of disparity}

178 We used Procrustes variance $(\mathrm{PV})$ to calculate disparity $[40,58]$ from our $2 \mathrm{D}(\mathrm{k} \times \mathrm{m} \times \mathrm{N})$

179 landmark dataset as: 


$$
S S W_{n}=\left(x_{1}-\overline{x_{1}}\right)^{2}+\left(y_{1}-\overline{y_{1}}\right)^{2}+\cdots+\left(x_{k}-\overline{x_{k}}\right)^{2}+\left(y_{k}-\overline{y_{k}}\right)^{2}
$$

180 where $S S W_{n}$ is the sum of the square distances between the coordinates $\left(x_{k}\right.$ and $\left.y_{k}\right)$ of

181 observation $n$, and their associated mean $\left(\overline{x_{k}}\right.$ and $\left.\overline{y_{k}}\right)$. This may be alternatively depicted as:

$$
S S W_{n}=\sum_{k=1}^{k}\left(x_{k}-\overline{x_{k}}\right)^{2}+\left(y_{k}-\overline{y_{k}}\right)^{2}
$$

182 All $S S W_{n}$ values in a given time-bin $t$ are then summed and divided by the sample size at that 183 time $\left(N_{t}\right)$ to measure PV, across all observations.

$$
P V_{t}=\frac{\sum_{n=1}^{n} S S W_{n}}{N_{t}}
$$

184 Disparity within each time-bin was partitioned according to our taxonomic order-level

185 classifications, which determined the clade-specific contributions to overall disparity. This

186 calculation equates to (2), but with distances measured relative to the mean of the group $i$

$187\left(\overline{x_{k \mid l}}\right)$, rather than the overall mean [48]:

$$
S S W_{n}=\sum_{k=1}^{k}\left(x_{k}-\overline{x_{k \mid l}}\right)^{2}+\left(y_{k}-\overline{y_{k \mid l}}\right)^{2}
$$

188 The partial $P V$ for the group $i$ over a specific time-bin $t$ is $\therefore$

$$
P V_{i \mid t}=\frac{\sum_{n=1}^{n} S S W_{n}}{n_{i}} \times \frac{n_{i}}{N-1}
$$

189 where $n_{i}$ is the sample size within group $i$ and $N$ is the total sample size within $t$.

190 Computationally, these equations are solved in geomorph [48], with the expectation that 191 additive partial disparities [59] for sampling within each time-bin approximate the total $P V$ 192 given $t$. 
193 We used a residual randomization permutation procedure (RRPP) with 1000 permutations

194 [55] to test null hypotheses for our multivariate shape data as:

$$
\begin{aligned}
& H_{0}:\left|P V_{t 1}-P V_{t 2}\right|=0 \\
& H_{A}:\left|P V_{t 1}-P V_{t 2}\right|>0
\end{aligned}
$$

195 where $H_{0}$ assumes that pairwise absolute differences between PVs across two given time-bins 196 (e.g. $t 1$ and $t 2$ ) will be zero. $H_{A}$ alternatively stipulates that the difference will be greater than 197 zero.

198 We also applied non-parametric bootstrap resampling to estimate confidence intervals around 199 disparity. All post-hoc pairwise comparisons of group-means were subject to false discovery 200 rate (FDR) adjustments for $P$-values to mitigate the increased risk of Type I errors associated 201 with multiple comparisons [60].

203 We accommodated for inherent sample size biases in the fossil record $[4,61-63]$ via

204 rarefaction to aid comparisons of time-scaled PV [20]. This involved sub-sampling all time-

205 bins to a minimum time-bin size (S1, S3 and S4 Table) 999 times, from which 95\%

206 prediction intervals were calculated. Geographic sub-sampling focused on the UNESCO

207 World Heritage fossil locality at Stevns Klint in Denmark (S8 Fig), which preserves

208 exceptionally rich selachimorph assemblages [64,65] spanning the K/Pg succession [66].

209 However, we also calculated partial disparities for each time-bin based first on depositional

210 basins, and then using countries of origin; designated $i$ in (5). Although geopolitical

211 boundaries are artificial, they provide a convenient proxy for comparing regional versus

212 global disparity signals across a broader sub-sample series. 
214 Sharks are known to exhibit both monognathic (MH, variation along the tooth row) and

215 dignathic (DH, variation between the upper and lower jaws) heterodonty $[8,67]$, which is

216 usually undetectable with isolated fossil teeth [68]. To attempt to remove potential

217 confounding factors associated with tooth position that may affect morphospace distributions

218 [20,69] we inferred all teeth to either parasymphyseal, anterior, lateroposterior, and posterior

219 tooth positions $\left(\mathrm{N}_{\mathrm{MH}}=897\right)$ and segregated teeth from the upper and lower tooth rows

$220 \quad\left(\mathrm{~N}_{\mathrm{DH}}=334\right)($ also see Supplementary Text).

Shape $\sim$ Tooth Position $+t$

222 where the aligned Procrustes coordinates (shape) are described as a function of monognathic

223 versus dignathic tooth position and age $(t)$.

224 Lastly, because developmental $[69,70]$ and ontogenetic factors $[69,71-73]$ are likewise

225 difficult to define from isolated teeth, we conducted our analyses with the caveat that

226 adequate intraspecific coverage was assumed for each order-level clade.

\section{Taxonomic richness}

228 We used an occurrence-based sub-sample to calculate taxonomic richness of sharks at genus-

229 level. Classic rarefaction (CR) and Shareholder Quorum Sub-sampling (SQS) $[61,74]$ were

230 implemented in the divDyn v. 0.8.0 package [75]. This employed a four-age time-binning

231 scheme with rarefaction constrained at a sub-sample size of 30, and the SQS quorum level at

2320.6 ([76]). Results were visualized as quantile plots.

\section{RESULTS}


236 Visual comparison of the computed consensus (mean) tooth shapes (S9 Fig) indicated very

237 low error margins. Accordingly, an intra-class correlation coefficient $(R)$ of $2 \%$ (or 1 in 50 )

238 was calculated based on the aligned Procrustes coordinates and their error replicate

239 counterparts $(\mathrm{N}=30)(\mathrm{S} 9$ Table), as well as Pearson's product-moment correlation $(\mathrm{t}=1874.7$,

$240 d f=9598, p$-value $<<0.001, R=0.99)$ and two-block partial least squares tests $(\mathrm{r}-\mathrm{pls}=0.997, p$ -

241 value=0.001, Z=7.136), which unambiguously demonstrate dataset compatibility (S10 Fig).

\section{PCA visualization}

243 PC1-4 explains $89.28 \%$ of the shape variation (Fig 1A-C, S11 Fig), with the other PC axes

244 describing less than 5\% (S11 Fig and S10 Table). PC1 (62\%) captures tooth height and width

245 variation from apicobasally tall and narrow teeth, to mesiodistally broad and low crowns (Fig

246 2A). PC2 (12\%) alternatively represents distally recurved teeth with low 'heels', versus

247 upright triangular teeth with lateral cusplets (Fig 2B). PC3 (11\%) tracks tall and conical, to

248 distally wide and recurved teeth with pronounced lateral cusplets (Fig 2C). PC4 (5\%) captures

249 a spectrum of short triangular teeth with reduced cusplets, to tall crowns with prominent

250 cusplets that equalled the main cusp in height (Fig 2D).

251 While there was substantial overlap in tooth morphologies between our sampled selachimorph

252 clades (Fig 1A-C), a general Procrustes one-way ANOVA found significant difference

253 between the group means and specific axes of variation (Table 1). This accords with visual

254 segregation between the clades in morphospace (Fig 1A-C), and is further illustrated by

255 relative measures of central tendency, distribution symmetries, test of normality and

256 multimodality (S11Table).

\section{Global and regional disparity}

258 We found overall stability in selachimorph global disparity across the Campanian-Thanetian

259 interval (Fig 3A, S12 Table). The only exception was a significant decline within the 
260 Selandian time-bin $\left(\mathrm{PV}_{\text {Danian }}=0.082 ; \mathrm{PV}_{\text {Selandian }}=0.042 ; p=0.033\right)$, which may be a product of

261 sampling (N=28) and/or uneven clade representation (S12 Fig). Disparity during the

262 Thanetian does exceed (Fig 3A, S13 Fig, S12 Table) that of the pre-extinction Campanian

263 time-bin $\left(\mathrm{PV}_{\text {Campanian }}=0.069 ; \mathrm{PV}_{\text {Thanetian }}=0.085 ; p=0.033\right)$, and was unaffected by pruning of

264 synechodontiforms, a group of possible stem selachimorphs (Fig 3A and S13 Table).

265 Comparisons with the Stevns Klint regional sub-sample found no significant change in tooth

266 disparity $\left(\mathrm{PV}_{\text {lateMaastrichtian }}=0.091 ; \mathrm{PV}_{\text {earlyDanian }}=0.069 ; p=0.106\right)$ across the $\mathrm{K} / \mathrm{Pg}$ boundary

267 event (Fig 3A and S14 Table). The extinction event was followed by a significant disparity

268 increase between the early to middle Danian $\left(\mathrm{PV}_{\text {earlyDanian }}=0.069 ; \mathrm{PV}_{\text {middleDanian }}=0.123\right.$;

$269 p=0.005)$.

270 Genus-level diversity

271 Raw genus-level occurrences showed a diversity increase in the Campanian to Maastrichtian

272 time-bins, followed by a prolonged decline throughout the Danian-Thanetian (Fig 3B).

273 However, sample-standardized curves using SQS and CR suggest stable diversity across the

274 extinction event (Fig 3B).

\section{Superorder-level clade disparity}

276 Relative stasis characterizes the disparity of both galeomorphs and squalomorphs across the

277 Maastrichtian-Danian time-bins (Fig 4A-B, S15-17 Table). This result was consistent even

278 after synechodontiforms were excluded (Fig 4A, S16 Table). Conversely, independent testing

279 of the Stevns Klint regional sub-sample produced a significant disparity increase among

280 galeomorphs ( $\left.\mathrm{PV}_{\text {earlyDanian }}=0.069 ; \mathrm{PV}_{\text {middleDanian }}=0.109 ; p=0.022\right)$ in the early-middle Danian

281 time-bins (Fig 4A, S18-19 Table), and a corresponding reduction in squalomorph disparity

282 (Fig 4B, S20 Table) in the late Maastrichtian-early Danian time-bins ( $\mathrm{PV}_{\text {lateMaastrichtian }}=0.077$;

$\left.283 \quad \mathrm{PV}_{\text {earlyDanian }}=0.041 ; p=0.005\right)$. 
Order-level clade disparity

285 Lamniform and carcharhiniform (Fig 5A-B, S21-22 Table) disparity returned maximum PV

286 from the Campanian and Maastrichtian (Fig 5A-B). Global lamniform disparity is stable

287 across the K/Pg boundary ( $\mathrm{PV}_{\text {Maastrichtian}}=0.070 ; \mathrm{PV}_{\text {Danian-Selandian }}=0.059 ; p=0.396 ;$ Fig $\left.5 \mathrm{~A}\right)$, and

288 shows no significant change by the Thanetian $\left(\mathrm{PV}_{\text {Maastrichtian }}=0.070 ; \mathrm{PV}_{\text {Thanetian }}=0.055\right.$;

$289 p=0.264 ;$ Fig 5A).

290 Carcharhiniforms exhibited a marked disparity decline from the Campanian to Danian-

291 Selandian with our global sample, but not with the Stevns Klint regional sub-sample (Fig 5B,

292 S22 Table). A distinct drop across the Campanian-Maastrichtian time-bins

$293\left(\mathrm{PV}_{\text {Campanian }}=0.085 ; \mathrm{PV}_{\text {Maastrichtian }}=0.056 ; p=0.024\right)$ was followed by a non-significant change

294 across the Maastrichtian-Danian-Selandian time-bins ( $\mathrm{PV}_{\text {Maastrichtian }}=0.056 ; \mathrm{PV}_{\text {Danian- }}$

295 Selandian $=0.041 ; p=0.125$ ), and a subsequent disparity increase from the Danian-Selandian-

296 Thanetian $\left(\mathrm{PV}_{\text {Danian-Selandian }}=0.041 ; \mathrm{PV}_{\text {Thanetian }}=0.061 ; p=0.020\right)($ Fig. $5 \mathrm{~B})$.

297 Heterodontiform disparity was uniform across the Campanian to Thanetian time-bins (Fig 5C,

298 S23 Table). On the other hand, orectolobiforms showed a significant disparity increase

299 (PV $\left.\mathrm{Pampanian}_{\text {}}=0.024 ; \mathrm{PV}_{\text {Danian-Selandian }}=0.064 ; p=0.016\right)$ from the Campanian to Danian-

300 Selandian time-bins (Fig 5D, S24 Table). Conversely, we recovered no significant change in

301 orectolobiform disparity between the Maastrichtian-Danian-Selandian time-bins

$302\left(\mathrm{PV}_{\text {Maastrichtian }}=0.041 ; \mathrm{PV}\right.$ Danian-Selandian $\left.=0.064 ; p=0.096\right)$, and neither while using our regional

303 sub-sample $\left(\mathrm{PV}_{\text {lateMaastrichtian }}=0.109 ; \mathrm{PV}_{\text {earlyDanian }}=0.066 ; p=0.294\right)$ (Fig. 5D).

304 Hexanchiforms disparity was statistically non-differentiable across the Maastrichtian-Danian-

305 Selandian time-bins ( $\left.\mathrm{PV}_{\text {Maastrichtian }}=0.018 ; \mathrm{PV}_{\text {Danian-Selandian }}=0.124 ; p=0.104\right)$, and also between

306 the Danian-Selandian and Thanetian time-bins ( $\mathrm{PV}$ Danian-Selandian $=0.124 ; \mathrm{PV}_{\text {Thanetian }}=0.054$;

$307 p=0.072$ ) (Fig 5E, S25 Table). Squaliforms similarly showed stable disparity from the 
308 Maastrichtian-Danian-Selandian time-bins $(p=0.084)$, both with global, and Stevns Klint

309 regional sub-sample data (Fig 5F, S26 Table). Finally, squatiniforms and synechodontiforms

310 were stable, but their small sample sizes make interpretations equivocal (Fig 5G-H, S27-S28

311 Table).

\section{Global partial disparity}

313 Our PV values indicate that selachimorph global disparity during the Campanian and

314 Maastrichtian was predominantly driven by lamniforms (Fig 6A). Not surprisingly,

315 lamniforms were also the most numerically abundant taxa in our dataset (S1 Fig). Lamniform

316 global disparity subsequently decreased in the Danian time-bin (Fig 6A), but increased again

317 in the Selandian time-bin. Altogether, lamniforms accounted for almost the total global

318 variance observed within Selachimorpha (Fig 6A). Carcharhiniforms and hexanchiforms

319 otherwise contributed towards a global disparity increase across the Danian-Thanetian time-

320 bins (Fig 6A).

321 Although sampling is admittedly uneven, our break-down of family-level clade disparity (Fig.

322 6B) indicates that archaeolamnids, mitsukurinids, and anacoracids are the primary drivers

323 within the Campanian time-bin. Odontaspidid sharks increase their disparity following the

324 extinction of anacoracids in the Danian-Selandian time-bin, and expanded substantially in the

325 Thanetian time-bin (Fig. 6B). In correspondence, triakids, hexanchids, and squalids were the

326 major non-lamniform contributors to disparity in the Danian-Selandian time-bin, with

327 scyliorhinids becoming dominant in the Thanetian time-bin. Other family-level clades, such

328 as ginglymostomatids and hexanchids also increased their disparity from the Danian-

329 Selandian to Thanetian time-bins (Fig. 6B). 
332 Samples from the Western Interior Basin (58\% derived entirely from the upper Judith River

333 Formation in the U.S.A) of North America and the Central and Northern European basins

334 accounted for most of the disparity in our Campanian time-bin (Fig 7A and S14 Fig).

335 Stratigraphically equivalent sequences from the Ouled Abdoun and Tarfaya basins of

336 Morocco $(\mathrm{N}=3)$ contributed comparatively limited disparity, although, the Moroccan sample

337 contributes substantially to the Maastrichtian signal (Fig 7B). In general, geographic regions

338 represented by small sub-samples exhibited low disparities, unlike large sub-sampled regions,

339 such as the U.S.A., which overwhelmingly contributed to global disparity in our

340 Maastrichtian time-bin (Fig 7B). Sub-age comparisons indicated that the U.S.A. sub-sample

341 was less dominant in the Maastrichtian time-bin, and was outweighed by the Stevns Klint

342 sub-sample combined with the Limhamn Quarry sub-sample from Sweden in our Danian-

343 Selandian time-bins (Fig 7C). Both the U.S.A. and Morocco sub-samples returned to high

344 disparity in the Thanetian time-bin (Fig 7D).

345 Effects of heterodonty on disparity

346 A significant disparity increase occurred across the Maastrichtian-Danian-Selandian time-

347 bins $\left(\mathrm{PV}_{\text {Maastrichtian }}=0.066 ; \mathrm{PV}\right.$ Danian-Selandian= $\left.0.082 ; p=0.032\right)$ with our monognathic

348 heterodonty model (S29-S30 Table). The combined monognathic and dignathic heterodonty

349 model also produced a disparity increase from the Campanian to Maastrichtian time-bins

350 ( $p=0.016)$. However, dignathic heterodonty, together with a multivariate

351 monognathic/dignathic heterodonty interaction model yielded no comparable disparity shifts

352 (S15 Fig and S29-S30 Table) across the K/Pg boundary. Finally, model comparisons revealed

353 largely consistent trajectories in dental disparity throughout the Campanian-Thanetian

354 interval, despite some effect (i.e., the inflation of absolute values) of heterodonty (S15 Fig). 
Pairwise comparisons along all PCs found significant differences in morphospace distribution between time-bins (Fig 8, Table 2). The PC1 distributions are platykurtic (kurtosis < 3) and positively skewed, except during the Thanetian, which was negatively skewed ( $g$ 1 Thanetian= 0.0336). Computed distribution-specific interquartile ranges (IQR) show minimal morphospace dispersion on PC2 (S31-S32 Table). A Hartigan's dip test of multimodality did

361 not reject a unimodal distribution on either PC1 or PC2. However, a significant positive

362 morphospace shift occurred between the Maastrichtian-Danian along PC1 (Fig 8A, S16 Fig,

363 S31-S32 Table). Notably, there was no corresponding change in the modal-shape

364 configurations, although a reduction in positively loaded morphospace accompanied range-

365 shortening among the minimum values (Fig 8A, S16 Fig).

366 The average value along PC1 shifted positively from the Selandian to the Thanetian (Fig 8A).

367 Comparisons between the Campanian-Maastrichtian $(p=0.025)$ and Maastrichtian versus

368 Thanetian time-bins ( $p=0.013)$ likewise yielded significant morphospace shifts (S33 Table).

369 The PC2 distribution was leptokurtic (high kurtosis > 3) during the Campanian and Danian,

370 but characterized by low kurtosis from the other time-bins (Fig 8B). A positive shift occurred

371 from the Maastrichtian ( $\left.g 1_{\text {Maastrichtian }}=-0.0806\right)$ to the Danian $\left(g 1_{\text {Danian }}=0.2833\right)($ Fig $8 \mathrm{~B}, \mathrm{~S} 31$

372 Table), and coincide with a loss of negatively loaded tooth morphologies (Fig 8B).

373 Nonetheless, the positive loading frequency diminished during the Danian, and a Procrustes

374 ANOVA also found statistical differentiation between the Campanian-Danian $(p=0.008)$ and

375 Maastrichtian-Danian $(p=0.015)$ time-bins (S33 Table). A comparable morphospace shift

376 across the K/Pg interval was detected with the four-age time-binning scheme (S13 Fig), and

377 incorporated subtle changes in modal-shape within the Campanian + Maastrichtian-Danian-

378 Selandian time-bins (S16 Fig). 
380 The Stevns Klint regional sub-sample reveals no substantial shifts along PC1 or PC2 from the

381 late Maastrichtian to the early Danian (Fig 9A-B, S33 Table). However, a significant sub-age

382 positive shift in mean morphology occurred along PC1 between the late Maastrichtian-middle

383 Danian $(p=0.005)$, and also between the early-middle Danian time-bins $(p=0.005)$ (Fig 9A,

384 S33 Table). Both, the late Maastrichtian ( $\left.g 1_{\text {late Maastrichtian }}=0.2640\right)$ and early Danian time-bins

385 ( $\left.g 1_{\text {early Danian }}=0.2957\right)$ are characterized by positively skewed distributions, but with negative

386 skewing during the middle Danian ( $\left.g 1_{\text {middle Danian }}=-0.1614\right)$. An increase in negatively loaded

387 teeth is associated with the early Danian along PC1; a pattern also reflected in the modal-

388 shape configuration (Fig. 9A).

389 The PC2 distribution was negatively skewed in the late Maastrichtian time-bin, while the

390 early-middle Danian time-bins exhibited positive skewing (Fig 9B, S33 Table). Modal shape

391 changes were more pronounced along PC2 (Fig 9B), with a gradual shift from negatively to

392 positively loaded values (Fig 9B).

\section{Superorder-level clade morphospace}

394 Galeomorphs and squalomorphs occupied comparable regions on PC1 throughout the entire

395 Maastrichtian-Thanetian interval (Fig 10A), but exhibit notable differences in their mean and

396 medial values. On average, galeomorphs are characterised by tall, narrow teeth, whereas

397 squalomorphs are low crowned. The most pronounced shift occurs across the K/Pg Boundary

398 along PC1, as well as on PC3 and PC4 (S34 Table), where galeomorphs exhibit a reduction in

399 negative PC1 values (Fig 10A). Squalomorphs underwent a significant positive shift on PC2

400 ( $p=0.016$ ) from the Maastrichtian to the Danian-Selandian (Fig 10A-B, S35 Table).

401 Order-level clade morphospace

402 Lamniforms display a significant positive shift in mean morphology along PC1 from the

403 Maastrichtian to Danian-Selandian time-bins ( $p=0.002$ ) (Fig 11A, S36 Table), concomitant 
404 with a shift in distribution patterns from positively to negatively skewed $\left(\mathrm{g} 1_{\text {Maastrichitan }}=0.5035\right.$;

$\left.405 g 1_{\text {Danian-Selandian }}=-0.3193\right)$. The frequency of negatively loaded morphologies on PC1 is low

406 during the Thanetian; the distribution of which is significantly different from both the

407 Campanian $(p=0.002)$ and the Maastrichtian $(p=0.002)$.

408 Carcharhiniforms alternatively exhibited a relatively stable morphospace along PC1 across

409 the K/Pg Boundary, although their distribution contracted (IQR Maastrichitan $=0.25 \mathrm{vs}$. IQR ${ }_{\text {Danian- }}$

410 Selandian=0.19). A significant negative shift between the Campanian and Danian-Selandian

411 time-bins $(p=0.024)$ is noted, along with a possible gradual transition from generally positive

412 to negative values (S37 Table), via the contraction of positive PC1 values (Fig 11A).

413 Heterodontiforms, orectolobiforms, hexanchiforms, squaliforms, squatiniforms, and

414 synechodontiforms all produced no significant deviations along PC1 in the Campanian to

415 Thanetian time-bins (Fig 11A, S38-S43Table).

416 On PC2, lamniforms exhibited a depletion of negative values from the Maastrichtian-Danian-

417 Selandian time-bins, and these are statistically different $(p=0.004)$ (Fig 11B). Pairwise

418 comparisons also recovered a significant difference between the Campanian and Danian-

419 Selandian time-bins ( $p=0.004)$. By contrast, carcharhiniforms show no major changes along

420 PC2, except for a slight increase in positive skewness across the Danian-Selandian-Thanetian

421 time-bins, which might imply an exploration of new morphospace (Fig 11B). We additionally

422 detected significant differences between the Campanian and Danian-Selandian $(p=0.031)$,

423 and the Campanian and Thanetian time-bins $(p=0.007)$, although this signal reduced after

424 FDR-adjustment of the $p$-values (S37 Table). No notable shifts were noted along PC2 for

425 heterodontiforms and orectolobiforms (Fig 11B). Yet, these clades did incline towards

426 positive skewness. Finally, no significant shifts in average morphology were noted along PC2

427 among squaliforms, squatiniforms, and synechodontiforms (S41-43 Table). 


\section{DISCUSSION}

\section{Disparity dynamics across the K/Pg Boundary}

430 Our results indicate that the global disparity of selachimorphs across the K/Pg extinction

431 event was largely stable. Stasis is consistent with previous dental disparity-based studies of

432 sharks [20] and interpretations of the elasmobranch fossil record [16], but contrasts with

433 significant losses in species richness of almost 50\% [17,18,77], suggesting shark diversity and

434 disparity were decoupled across the K/Pg Boundary. Importantly, our evidence for static

435 disparity in selachimorphs across the boundary is retained after accounting for heterodonty

436 and differences in order-level representation between the K/Pg time-bins (S15 Fig). Overall,

437 we find that these sources of variation only alter the disparity inferred for the Thanetian that,

438 upon correction, cannot be differentiated from that of the Campanian (see Fig. 3A, S15 Fig,

439 and S29 Table). In either case, morphological stasis about the K/Pg Boundary suggests that

440 the loss of $17 \%$ of families [17] was not linked to major losses in ecological diversity and,

441 overall, conforms to a 'non-selective' extinction model [78]. However, at lower taxonomic

442 scales, lamniforms experienced the selective extinction of Cretaceous anacoracids [20] with

443 triangular, blade-like teeth (Fig 11A-B) and, in the aftermath, lamniform morphospace

444 underwent a noticeable Paleocene proliferation of apicobasally tall, laterally cusped teeth,

445 driven by odontaspidids (Fig 11A-B). This dynamic of loss in one area of morphospace and

446 subsequent proliferation in another supports a 'shift' extinction model [20], the result of

447 which is a stable disparity. Concomitantly, carcharhiniforms characterized by mesiodistally

448 broad and low teeth proliferated during the Paleocene (Fig 11A-B), perhaps reflecting a 'non-

449 adaptive' radiation along with minimal ecological divergence [20]. In comparison to

450 galeomorphs, squalomorph disparity seemed largely unaffected by the extinction event,

451 despite previously identified moderate taxonomic losses among squalids [17]. Much like the

452 overall pattern, squalids may have undergone a non-selective extinction. However, 
squalomorphs remain poorly sampled across the end-Cretaceous extinction event (S1 Table),

454 and associated patterns should be interpreted cautiously.

455 Despite the proliferation of certain tooth types in the aftermath of the extinction event, static

456 disparity does not support a Paleocene diversification of sharks, which is in contrast to the

457 substantial ecological and taxic diversification of coeval actinopterygian fishes (e.g.,

458 acanthomorphs and carangarians) [16,19,79-82]. Nevertheless, Sibert et al. [83] recently

459 found that post-Mesozoic actinopterygian disparity underwent alteration in only a few

460 dominant tooth morphotypes. Likewise, we suggest that while, in general, sharks do not seem

461 to have experienced much change in disparity across the $\mathrm{K} / \mathrm{Pg}$ boundary, they did suffer

462 sufficient ecological disturbance to trigger a compositional transformation in the diversity of

463 certain constituent clades [20,83], such as lamniform and carcharhiniforms.

\section{Regional-and global-level extinction dynamics}

465 Adolfssen \& Ward [64] reported a 33\% decline in chondrichthyan richness across the K/Pg

466 extinction interval sampled at Stevns Klint in Denmark, which is substantially less than that

467 reported from Morocco ( 96\%: [84]) or globally ( 84\%: [17]). Stevns Klint preserves a

468 largely endemic Boreal fauna [64], yet its static disparity signal is largely indistinguishable

469 from that recovered by our global disparity analysis. However, a slight disparity increase (Fig.

$4703 \mathrm{~A}$ ) was recovered from the early to middle Danian, which conforms to an overall increase

471 (albeit statistically non-significant) in absolute values amongst galeomorphs (Fig. 4A). This

472 regional pattern is indicative of likely short-term recovery in the aftermath of the extinction

473 event, but otherwise posit a direct correlation with distribution trends evidenced globally for

474 the early Paleocene.

475 On a broader level, regional disparity occurred in 'hotspots' that transitioned over the sampled

476 interval. Results indicate that (1) the Western Interior Basin assemblages from the U.S.A. 
477 contributed to much of the measurable global disparity during the Campanian and

478 Maastrichtian (Fig 7A-B); (2) the Scandinavian Boreal assemblages from Denmark and

479 Sweden likewise predominate disparity for the K/Pg extinction interval (Fig 7C and S14 Fig);

480 and (3) the Mediterranean Tethyan and Atlantic margin basins of Morocco provide most of

481 the disparity for the Thanetian (Fig 7D). While these results are clearly influenced by

482 preservation biases (e.g., spatial variation in sampling across the Cretaceous/Paleogene

483 Boundary) (as is typical of many fossil vertebrates: [85]), they also highlight underlying

484 provincialism, and noticeably correlate with the changing depositional context of northern

485 mid-latitude epicontinental habitats during the Cretaceous-Paleocene timeframe. For instance,

486 the steady disparity decline in North America correlates with the regression of the Western

487 Interior Seaway across this interval [86]. Therefore, despite overall consistent patterns

488 between global and regional disparity profiles (when assessing the Denmark sub-sample), we

489 suggest that extinction and recovery dynamics of sharks varied globally, as previously

490 documented for other post-mass extinction marine ecosystems [87-89]. Moreover, it is

491 possibly that selachimorphs survived the $\mathrm{K} / \mathrm{Pg}$ crisis in epeiric refugia [64] and subsequently

492 'radiated' from localised diversification centers.

494 The reorganization of selachimorph communities across the K/Pg mass extinction event

$495[17,18,20,24]$ can almost exclusively be attributed to large body-sized, apex-predatory

496 anacoracid lamniforms (e.g., the reduction of negatively loaded tooth structures) [20,21].

497 Such patterns are consistent with the loss of other marine apex predators, such as mosasaurs

498 and plesiosaurs at the end of the Mesozoic [90-92]. Unlike marine tetrapods, which would

499 not return until the Eocene, the extinction of Cretaceous anacoracids was immediately

500 followed by the appearance of large-bodied hexanchiforms in some earliest Paleocene

501 deposits (e.g., the Limhamn quarry) [93]. Anacoracids and hexanchids exhibit substantial 
502 morphospace overlap, especially along PC1, (S17 Fig), suggesting at least some ecological

503 equivalency, which is supported by modern-day observations that the hexanchid Notorynchus cepedianus becomes more abundant following the removal of the large-bodied lamniform,

505 Carcharodon carcharias [94]. Unfortunately, there is at present no universal approach for

506 estimating the body sizes of fossil sharks from their teeth (but see: [95]), and further

507 paleoecological comparisons between hexanchids and lamniforms remain ambiguous.

508 Regardless, the continuity of large-bodied sharks across the boundary, does suggest that

509 extinction susceptibility was not limited to relative body-size. Indeed, studies on living

510 cartilaginous fishes have shown that habitat preferences and reproductive strategies play a

511 more important role in determining survival, whereas, body-size has a modest effect on

512 extinction risk [96].

513 Finally, for sharks, the K/Pg event should also be viewed in terms of diversification, rather

514 than simply extinction. In particular, lamniforms (odontaspidids) and carcharhiniforms

515 (triakids, scyliorhinids) morphologically proliferated in the early Paleocene, potentially taking

516 advantage of teleost fishes as an newly emergent food resource [16]. These patterns, highlight

517 the importance of biotic factors (i.e., predator-prey relationship) within the context of global

518 mass extinction, and it's contrasting effect among shark groups.

\section{CONCLUSIONS}

520 Understanding the evolutionary dynamics of sharks during the catastrophic end-Cretaceous

521 mass extinction event $[17,18,20,21,77]$ has analytically lagged behind assessments of other

522 dominant marine vertebrate groups such as teleost fishes [16,19,79-82], and

523 marine/freshwater reptiles [91,92,97,98]. Consequently, we present the first comprehensive

524 geometric morphometric evaluation of selachimorph disparity across multiple clades based on

525 their prolific dental fossil record. The combined observation of virtually static levels of 
morphological disparity and the potential for differential extinction dynamics across the globe suggest that, in a broad sense, the $\mathrm{K} / \mathrm{Pg}$ extinction event was not as severe for sharks, as it was for other vertebrates $[90,91,99,100]$ Nevertheless, one particularly dominant Mesozoic clade of sharks, anacoracid lamniforms, underwent a selective extinction, which saw to the loss of

530 triangular, blade-like teeth that were perhaps associated with feeding on large-bodied

531 contemporaneous tetrapods [20]. Other coeval selachimorph clades, however, survived and appear of have been largely unaffected by the extinction event, with some groups of changes in their morphology, but without substantial modifications to their overall disparity

536 [20]. The potential drivers of this transition include possible shifts in food resources,

537 supported by the Paleocene diversification of teleost fishes, although other mechanisms cannot be rejected at this time. Finally, our application of a morphospace-disparity framework offers a powerful interpretive tool that compliments traditional taxonomy-based assessments

540 of discrete character data [e.g., 101,102]. We therefore advocate similar continuously valued

541 disparity descriptors to reconstruct deep time evolutionary patterns in the fossil record of

542 sharks in the future, while acknowledging that variation sources, such as heterodonty and

543 differential spatiotemporal sampling, need to be accommodated.

\section{ACKNOWLEDGEMENTS}

545 We thank Jesper Milan (Geomuseum Faxe) and Mikael Siversson (Western Australian

546 Museum) for discussions and access to material. Daniel Snitting (Uppsala University) assisted

547 with processing of image data. Julien Claude (Université de Montpellier), Göran Arnqvist

548 (Uppsala University), Grahame Lloyd (University of Leeds), Dean Adams (Iowa State

549 University), and Michael L. Collyer (Chatham University) contributed expertise on the

550 morphometric and statistical analyses. Our research was financed by The Royal Swedish 
Academy of Sciences (GS2017-0018) to M.B., and a Wallenberg Scholarship from the Knut

and Alice Wallenberg Foundation to P.E.A. B.P.K. also acknowledges funding from a

Swedish Research Council Project Grant (2020-3423), and N.E.C. is funded by an Australian

Research Council Discovery Early Career Research Grant (DE190101423).

\section{DATA ARCHIVING STATEMENT}

Data and supporting information for this study are available in the Dryad Digital Repository.

\section{LITTERATURE CITED}

558 1. Sepkoski JJ, Bambach RK, Raup DM, Valentine JM. Phanerozoic marine diversity and the fossil record. Nature. 1981. pp. 435-437. doi:10.1038/293435a0

560 2. Benton MJ. Diversification and extinction in the history of life. Science (80- ). 1995;268: 52-58. doi:10.1126/science.7701342

562 3. Benton MJ. Exploring macroevolution using modern and fossil data. Proc R Soc B Biol Sci. 2015;282. doi:10.1098/rspb.2015.0569

564 4. Raup DM. Taxonomic diversity during the phanerozoic. Science. 1972. doi:10.1126/science.177.4054.1065

5. Smith AB. Large-scale heterogeneity of the fossil record: Implications for phanerozoic biodiversity studies. Philos Trans R Soc B Biol Sci. 2001. doi:10.1098/rstb.2000.0768

568 6. Smith AB, McGowan AJ. The shape of the phanerozoic marine palaeodiversity curve: How much can be predicted from the sedimentary rock record of Western Europe? Palaeontology. 2007. doi:10.1111/j.1475-4983.2007.00693.x

571 7. Upchurch P, Mannion PD, Benson RBJ, Butler RJ, Carrano MT. Geological and anthropogenic controls on the sampling of the terrestrial fossil record: A case study from the dinosauria. Geol Soc Spec Publ. 2011. doi:10.1144/SP358.14

574 8. Cappetta H. Handbook of Paleoichthyology Volume 3E: Chondrichthyes - Mesozoic 
and Cenozoic Elasmobranchii: Teeth. Munich, Germany: Verlag Dr. Friedrich Pfeil; 2012.

577 9. Guinot G, Adnet S, Shimada K, Underwood CJ, Siversson M, Ward DJ, et al. On the need of providing tooth morphology in descriptions of extant elasmobranch species. Zootaxa. 2018. doi:10.11646/zootaxa.4461.1.8

10. Weigmann S. Annotated checklist of the living sharks, batoids and chimaeras (Chondrichthyes) of the world, with a focus on biogeographical diversity. J Fish Biol. 2016. doi:10.1111/jfb.12874

11. Stein RW, Mull CG, Kuhn TS, Aschliman NC, Davidson LNK, Joy JB, et al. Global priorities for conserving the evolutionary history of sharks, rays and chimaeras. Nat Ecol Evol. 2018;2: 288-298. doi:10.1038/s41559-017-0448-4

12. Dulvy NK, Fowler SL, Musick JA, Cavanagh RD, Kyne PM, Harrison LR, et al. Extinction risk and conservation of the world's sharks and rays. Elife. 2014. doi:10.7554/elife.00590

13. Ferretti F, Worm B, Britten GL, Heithaus MR, Lotze HK. Patterns and ecosystem consequences of shark declines in the ocean. Ecology Letters. 2010. doi:10.1111/j.1461-0248.2010.01489.x

14. Queiroz N, Humphries NE, Couto A, Vedor M, da Costa I, Sequeira AMM, et al. doi:10.1038/s41586-019-1444-4

595 15. Roff G, Brown CJ, Priest MA, Mumby PJ. Decline of coastal apex shark populations over the past half century. Commun Biol. 2018. doi:10.1038/s42003-018-0233-1 
600 17. Kriwet J, Benton MJ. Neoselachian (Chondrichthyes, Elasmobranchii) diversity across the Cretaceous-Tertiary boundary. Palaeogeogr Palaeoclimatol Palaeoecol. 2004. doi:10.1016/j.palaeo.2004.02.049

18. Guinot G, Cavin L. 'Fish' (Actinopterygii and Elasmobranchii) diversification patterns through deep time. Biol Rev. 2016;91: 950-981. doi:10.1111/brv.12203

19. Sibert E, Norris R, Cuevas J, Graves L. Eighty-five million years of pacific ocean gyre ecosystem structure: Long-term stability marked by punctuated change. Proc R Soc B Biol Sci. 2016. doi:10.1098/rspb.2016.0189

20. Bazzi M, Kear BP, Blom H, Ahlberg PE, Campione NE. Static Dental Disparity and Morphological Turnover in Sharks across the End-Cretaceous Mass Extinction. Curr Biol. 2018. doi:10.1016/j.cub.2018.05.093

611 21. Belben RA, Underwood CJ, Johanson Z, Twitchett RJ. Ecological impact of the endCretaceous extinction on lamniform sharks. PLoS One. 2017. doi:10.1371/journal.pone.0178294

614 22. Ikejiri T, Lu YH, Zhang B. Two-step extinction of Late Cretaceous marine vertebrates in northern Gulf of Mexico prolonged biodiversity loss prior to the Chicxulub impact. Sci Rep. 2020. doi:10.1038/s41598-020-61089-w

23. Miller KG, Sugarman PJ, Browning J V., Kominz MA, Hernández JC, Olsson RK, et al. Late Cretaceous chronology of large, rapid sea-level changes: Glacioeustasy during the greenhouse world. Geology. 2003. doi:10.1130/0091-

621 24. Friedman M, Sallan LC. Five hundred million years of extinction and recovery: A phanerozoic survey of large-scale diversity patterns in fishes. Palaeontology. 2012;55: 707-742. doi:10.1111/j.1475-4983.2012.01165.x

624 25. Claude J. Morphometrics with R. Springer Science \& Business Media; 2008. 
Available: https://www.researchgate.net/publication/258885233

26. Webster M, Sheets HD. A Practical Introduction to Landmark-Based Geometric Morphometrics. Paleontol Soc Pap. 2010. doi:10.1017/s1089332600001868

27. Gottfried MD, Rabarison JA. First Mesozoic Gondwanan record of a sawshark (Chondrichthyes, Pristiophoriformes), from the Late Cretaceous of Madagascar. J Vertebr Paleontol. 1997. doi:10.1080/02724634.1997.10011022

28. De Carvalho MR. Higher-Level Elasmobranch Phylogeny, Basal Squaleans, and Paraphyly. Interrelationships of Fishes. 1996. doi:10.1016/b978-012670950-6/50004-7

29. Naylor GJ, Caira JN, Jensen K, Rosana K a., Straube N, Lakner C. Elasmobranch their relatives. 2012. doi:10.1080/17451000.2012.745005

30. Ebert DA, Fowler SL, Compagno LJ. Sharks of the World: A Fully Illustrated Guide. Wild Nature Press; 2013.

31. Maisey JG. Cranial Morphology of the Fossil Elasmobranch Synechodus dubrisiensis. Am Museum Novit. 1985.

32. Klug S, Kriwet J, BÖttcher R, Schweigert G, Dietl G. Skeletal anatomy of the extinct shark Paraorthacodus jurensis (Chondrichthyes; Palaeospinacidae), with comments on synechodontiform and palaeospinacid monophyly. Zool J Linn Soc. 2009.

644 33. Klug S. Monophyly, phylogeny and systematic position of the $\uparrow$ synechodontiformes (Chondrichthyes, Neoselachii). Zool Scr. 2010. doi:10.1111/j.1463-6409.2009.00399.x

646 34. Maisey JG. What is an "elasmobranch"? The impact of palaeontology in understanding elasmobranch phylogeny and evolution. J Fish Biol. 2012;80: 918-951. doi:10.1111/j.1095-8649.2012.03245.x

649 35. Cohen KM, Finney SC, Gibbard PL, Fan JX. The ICS international chronostratigraphic 
chart. Episodes. 2013. doi:10.18814/epiiugs/2013/v36i3/002

651 36. Bookstein FL. Morphometric Tools for Landmark Data. Morphometric Tools for Landmark Data. Cambridge University Press; 1992. doi:10.1017/cbo9780511573064

653 37. Dryden IL, Mardia K V. Statistical shape analysis: with applications in R. Second edi. Ltd,; 2016. doi:10.1002/9781119072492

38. Slice DE. Geometric Morphometrics. Annu Rev Anthropol. 2007. doi:10.1146/annurev.anthro.34.081804.120613

39. Adams DC, Rohlf FJ, Slice DE. Geometric morphometrics: Ten years of progress following the 'revolution.’ Ital J Zool. 2004. doi:10.1080/11250000409356545

40. Zelditch M, Swiderski D, Sheets H. Geometric Morphometrics for Biologists. Geometric Morphometrics for Biologists. 2012. doi:10.1016/C2010-0-66209-2

41. Mitteroecker P, Gunz P. Advances in Geometric morphometrics. Evol Biol. 2009.

664 42. Bookstein FL. Morphometric Tools for Landmark Data. Morphometric Tools for Landmark Data. Cambridge University Press; 1991. doi:10.1017/cbo9780511573064

43. Rohlf FJ. tpsDig. Available from http//life.bio.sunysb.edu/morph/. 2016. doi:10.1093/jac/dkf017

44. Team RC. R: A Language and Environment for Statistical Computing. Vienna, Austria. 2019.

670 45. Moyer JK, Bemis WE. Shark teeth as edged weapons: serrated teeth of three species of selachians. Zoology. 2017;120: 101-109. doi:10.1016/j.zool.2016.05.007 
675 47. Yezerinac SM, Lougheed SC, Handford P. Measurement error and morphometric studies: Statistical power and observer experience. Syst Biol. 1992. doi:10.1093/sysbio/41.4.471

48. Adams D, Collyer M, Kaliontzopoulou A, Sherratt E. Geomorph: Software for geometric morphometric analyses. R package version 3.2.1. 2020. Available: https://cran.r-project.org/package=geomorph

49. Rohlf FJ, Slice D. Extensions of the procrustes method for the optimal superimposition of landmarks. Syst Zool. 1990. doi:10.2307/2992207

683 50. Bookstein FL. Landmark methods for forms without landmarks: Morphometrics of group differences in outline shape. Med Image Anal. 1997. doi:10.1016/S1361$8415(97) 85012-8$

51. Gunz P, Mitteroecker P, Bookstein FL. Semilandmarks in Three Dimensions. Modern Morphometrics in Physical Anthropology. 2006. doi:10.1007/0-387-27614-9_3

52. Bonhomme V, Picq S, Gaucherel C, Claude J. Momocs: Outline analysis using R. J

690 53. MacLeod N. Form \& shape models. Palaeontol Newsl. 2009;18: 1-11.

691 54. Olsen AM. Feeding ecology is the primary driver of beak shape diversification in waterfowl. Funct Ecol. 2017;31: 1985-1995. doi:10.1111/1365-2435.12890

693 55. Collyer ML, Adams DC. RRPP: An r package for fitting linear models to highdimensional data using residual randomization. Methods Ecol Evol. 2018.

696 56. Wickham H. ggplot2 Elegant Graphics for Data Analysis. Journal of the Royal Statistical Society: Series A (Statistics in Society). 2016. doi:10.1007/978-3-319$24277-4$

699 57. Korkmaz S, Goksuluk D, Zararsiz G. MVN: An R package for assessing multivariate 
normality. R J. 2014. doi:10.32614/rj-2014-031

701 58. Zelditch ML, Sheets HD, Fink WL. The ontogenetic dynamics of shape disparity. Paleobiology. 2003. doi:10.1666/0094-8373(2003)029<0139:todosd>2.0.co;2

59. Foote M. Contributions of individual taxa to overall morphological disparity.

Paleobiology. 1993. doi:10.1017/S0094837300014056

60. Benjamini Y, Hochberg Y. Controlling the False Discovery Rate: A Practical and Powerful Approach to Multiple Testing. J R Stat Soc Ser B. 1995. doi:10.1111/j.25176161.1995.tb02031.x

61. Alroy J. Geographical, environmental and intrinsic biotic controls on Phanerozoic marine diversification. Palaeontology. 2010. doi:10.1111/j.1475-4983.2010.01011.x

62. Close RA, Benson RBJ, Upchurch P, Butler RJ. Controlling for the species-area effect supports constrained long-term Mesozoic terrestrial vertebrate diversification. Nat Commun. 2017. doi:10.1038/ncomms15381

63. Mannion PD, Chiarenza AA, Godoy PL, Cheah YN. Spatiotemporal sampling patterns in the 230 million year fossil record of terrestrial crocodylomorphs and their impact on diversity. Palaeontology. 2019. doi:10.1111/pala.12419

64. Adolfssen JS, Ward DJ. Crossing the boundary: An elasmobranch fauna from Stevns Klint, Denmark. Palaeontology. 2014. doi:10.1111/pala.12079

65. Adolfssen JS, Ward DJ. Neoselachians from the Danian (early Paleocene) of Denmark. Acta Palaeontol Pol. 2015. doi:10.4202/app.2012.0123

66. Alvarez LW, Alvarez W, Asaro F, Michel H V. Extraterrestrial cause for the Cretaceous-Tertiary extinction. Science (80- ). 1980. doi:10.1126/science.208.4448.1095

723 67. Huber D, Wilga C, Dean M, Ferry L, Gardiner J, Habegger L, et al. Feeding in 
295. doi:10.1007/978-3-030-13739-7_8

76. Benson RBJ, Butler RJ, Alroy J, Mannion PD, Carrano MT, Lloyd GT. Near-Stasis in the Long-Term Diversification of Mesozoic Tetrapods. PLoS Biol. 2016.

68. Shimada K. Dental homologies in lamniform sharks (Chondrichthyes:

Elasmobranchii). J Morphol. 2002. doi:10.1002/jmor.1073

69. Cullen JA, Marshall CD. Do sharks exhibit heterodonty by tooth position and over ontogeny? A comparison using elliptic Fourier analysis. J Morphol. 2019;280: 687700. doi:10.1002/jmor.20975

70. Tomita T, Miyamoto K, Kawaguchi A, Toda M, Oka SI, Nozu R, et al. Dental ontogeny of a white shark embryo. J Morphol. 2017. doi:10.1002/jmor.20630

71. Jablonski D. Micro- and macroevolution: Scale and hierarchy in evolutionary biology and paleobiology. Paleobiology. 2000. doi:10.1017/s0094837300026877

72. Gerber S. On the Relationship between the Macroevolutionary Trajectories of Morphological Integration and Morphological Disparity. PLoS One. 2013. doi:10.1371/journal.pone.0063913

73. Berio F, Evin A, Goudemand N, Debiais-Thibaud M. The intraspecific diversity of tooth morphology in the large-spotted catshark Scyliorhinus stellaris: insights into the ontogenetic cues driving sexual dimorphism. J Anat. 2020. doi:10.1111/joa.13257

74. Raup DM. Taxonomic diversity estimation using rarefaction. Paleobiology. 1975. doi:10.1017/s0094837300002633

75. Kocsis ÁT, Reddin CJ, Alroy J, Kiessling W. The r package divDyn for quantifying diversity dynamics using fossil sampling data. Methods Ecol Evol. 2019. doi:10.1111/2041-210X.13161 doi:10.1371/journal.pbio.1002359

77. Guinot G, Adnet S, Cappetta H. An Analytical Approach for Estimating Fossil Record 
and Diversification Events in Sharks, Skates and Rays. PLoS One. 2012. doi:10.1371/journal.pone.0044632

78. Foote M. Discordance and concordance between morphological and taxonomic diversity. Paleobiology. 1993. doi:10.1017/S0094837300015864

79. Friedman M. Explosive morphological diversification of spiny-finned teleost fishes in the aftermath of the end-Cretaceous extinction. Proceedings of the Royal Society B: Biological Sciences. 2010. doi:10.1098/rspb.2009.2177

80. Miya M, Friedman M, Satoh TP, Takeshima H, Sado T. Evolutionary Origin of the Scombridae (Tunas and Mackerels): Members of a Paleogene Adaptive Radiation with 14 Other Pelagic Fish Families. PLoS One. 2013;8: 73535. doi:10.1371/journal.pone.0073535

81. Near TJ, Dornburg A, Eytan RI, Keck BP, Smith WL, Kuhn KL, et al. Phylogeny and tempo of diversification in the superradiation of spiny-rayed fishes. Proc Natl Acad Sci U S A. 2013. doi:10.1073/pnas.1304661110

82. Ribeiro E, Davis AM, Rivero-Vega RA, Ortí G, Betancur R. Post-Cretaceous bursts of evolution along the benthic-pelagic axis in marine fishes. Proc R Soc B Biol Sci. 2018. doi:10.1098/rspb.2018.2010

83. Sibert E, Friedman M, Hull P, Hunt G, Norris R. Two pulses of morphological diversification in Pacific pelagic fishes following the Cretaceous-Palaeogene mass extinction. Proceedings of the Royal Society B: Biological Sciences. 2018. doi:10.1098/rspb.2018.1194

771 84. Noubhani, A., Cappetta H. Les Orectolobiformes, Carcharhiniformes et Myliobatiformes (Elasmobranchii, Neoselachii) des Bassins a phosphate du Maroc (Maastrichtien-Lutetien basal): systématique, biostratigraphie, évolution et dynamique des faunes. Palaeo Ichthyol. 1997; 8:327. 
775 85. Jackson JBC, Johnson KG. Measuring past biodiversity. Science. 2001.

93. Siverson M. Revision of the danian cow sharks, sand tiger sharks, and goblin sharks doi:10.1126/science. 1063789

86. Cochran JK, Landman NH, Turekian KK, Michard A, Schrag DP. Paleoceanography of the Late Cretaceous (Maastrichtian) Western Interior Seaway of North America: Evidence from Sr and O isotopes. Palaeogeogr Palaeoclimatol Palaeoecol. 2003. doi:10.1016/S0031-0182(02)00642-9

87. Jablonski D. Geographic Variation in the Molluscan Recovery from the EndCretaceous Extinction. science.sciencemag.org. 1998. Available: http://science.sciencemag.org/

88. Patzkowsky AZK and ME. Geographic variation in turnover and recovery from the Late Ordovician mass extinction. Paleobiology. 2007;33: 435-454. Available: https://pubs.geoscienceworld.org/paleobiol/article-abstract/33/3/435/86456

89. Zatoń M, Niedźwiedzki G, Blom H, Kear BP. Boreal earliest Triassic biotas elucidate globally depauperate hard substrate communities after the end-Permian mass extinction. Sci Rep. 2016;6: 1-10. doi:10.1038/srep36345

90. Benson RBJ, Butler RJ. Uncovering the diversification history of marine tetrapods: Ecology influences the effect of geological sampling biases. Geol Soc Spec Publ. 2011. doi:10.1144/SP358.13

91. Martin JE, Vincent P, Tacail T, Khaldoune F, Jourani E, Bardet N, et al. Calcium Isotopic Evidence for Vulnerable Marine Ecosystem Structure Prior to the K/Pg Extinction. Curr Biol. 2017;27: 1641-1644.e2. doi:10.1016/j.cub.2017.04.043

92. Bardet N. Extinction Events Among Mesozoic Marine Reptiles. Hist Biol. 1994. doi:10.1080/10292389409380462

$$
\text { (hexanchidae, odontaspididae, and mitsukurinidae) from southern Sweden. J Vertebr }
$$


Paleontol. 1995. doi:10.1080/02724634.1995.10011203

801 94. Hammerschlag N, Williams L, Fallows M, Fallows C. Disappearance of white sharks leads to the novel emergence of an allopatric apex predator, the sevengill shark. Sci Rep. 2019. doi:10.1038/s41598-018-37576-6

804 95. Shimada K, Becker MA, Griffiths ML. Body, jaw, and dentition lengths of macrophagous lamniform sharks, and body size evolution in Lamniformes with special reference to 'off-the-scale' gigantism of the megatooth shark, Otodus megalodon. Hist Biol. 2020. doi:10.1080/08912963.2020.1812598

96. García VB, Lucifora LO, Myers RA. The importance of habitat and life history to extinction risk in sharks, skates, rays and chimaeras. Proc R Soc B Biol Sci. 2008. doi:10.1098/rspb.2007.1295

811 97. Polcyn MJ, Jacobs LL, Araújo R, Schulp AS, Mateus O. Physical drivers of mosasaur evolution. Palaeogeogr Palaeoclimatol Palaeoecol. 2014. doi:10.1016/j.palaeo.2013.05.018

814 98. Cleary TJ, Benson RBJ, Holroyd PA, Barrett PM. Tracing the patterns of non-marine turtle richness from the Triassic to the Palaeogene: from origin to global spread. Palaeontology. 2020. doi:10.1111/pala.12486

817 99. Field DJ, Bercovici A, Berv JS, Dunn R, Fastovsky DE, Lyson TR, et al. Early Mass Extinction. Curr Biol. 2018. doi:10.1016/j.cub.2018.04.062

820 100. Chiarenza AA, Farnsworth A, Mannion PD, Lunt DJ, Valdes PJ, Morgan J V., et al. Asteroid impact, not volcanism, caused the end-Cretaceous dinosaur extinction. Proc Natl Acad Sci U S A. 2020. doi:10.1073/pnas.2006087117

823 101. Hetherington AJ, Sherratt E, Ruta M, Wilkinson M, Deline B, Donoghue PCJ. Do cladistic and morphometric data capture common patterns of morphological disparity? 
bioRxiv preprint doi: https://doi.org/10.1101/2021.01.20.427414; this version posted January 20, 2021. The copyright holder for this preprint (which was not certified by peer review) is the author/funder, who has granted bioRxiv a license to display the preprint in perpetuity. It is made available under aCC-BY 4.0 International license.

Palaeontology. 2015. doi:10.1111/pala.12159

826 102. Brusatte SL, Benton MJ, Ruta M, Lloyd GT. Superiority, competition, and 


\section{FIGURE CAPTIONS}

832 FIG. 1. Morphospace distribution. (A) Multivariate shape space for the $n=1239$ global selachimorph

833 teeth sample. Theoretical backtransform tooth shapes (grey) indicate shape variability across

834 morphospace as defined by PC1 and PC2. (B-C) Box-and-whisker plots indicating average

835 morphospace occupation along (B) PC1, and (C) PC2. Error bars represent 95\% confidence intervals.

836 Proportion of variance and group sample sizes are listed in the axis labels.

837 FIG. 2. Hypothetical morphologies corresponding to the minimum and maximum values of

838 PC1-PC4. (A-D) Isolines and counter lines based on the TPS-method. Areas of concentrated strain

839 are indicated by increasing red intensity.

840 FIG. 3. Global and regional level disparity of Selachimorpha. (A) Dental disparity with

841 bootstrapped prediction intervals for the five and four-age time-binning schemes. The five-age time-

842 binning scheme $(n=1156)$ utilized sample-rarefaction on the lowest sampled Selandian time-bin

$843(n=28)$. The four-age time-binning scheme $(n=1198)$ used the Thanetian $(n=187)$. Rarefied disparity is

844 not shown for the Selandian (five-age time-bin) and middle Danian regional sub-sample (three-age

845 time-bin). (B) Raw, rarefied, and SQS corrected taxonomic sampled-in-bin 'SIB' diversity through time.

846 Shaded areas=quantiles. Sel=Selandian.

847 FIG. 4. Superorder-level clade disparity profiles. (A-B) Global/regional raw and rarefied dental-

848 disparity trajectories for Galeomorphii (including and excluding †Synechodontiformes) and

849 Squalomorphii.

850 FIG. 5. Global and regional clade-specific (order-level) disparity profiles. (A-D) Temporal

851 resolution varies between groups but broadly tracks the time-binned $\mathrm{K} / \mathrm{Pg}$ interval.

852 FIG. 6. Order and family level partial disparity. (A-B) Grouped bar plot depicting clade-level

853 contributions (pPV) to overall disparity in each time-bin. (B) Families with sample sizes of $n<5$ were

854 omitted. Resulting data: a total of 26 families and 1039 specimens when using the global four-age

855 time-binning scheme.

856 FIG. 7. Geographic distribution of disparity. (A-D) Partial disparities mapped using the global four-

857 age time-binning scheme. Colour gradient represents low-to-high disparity. 
858 FIG. 8. Global morphospace time-series. (A-B) Jittered box-plots visualizing the distribution of time-

859 bins along PC1 and PC2. Graph depicts patterns of overall shape change using the five-age time-

860 binning scheme. Arithmetic mean with 95\% confidence limits were derived via non-parametric

861 bootstrapping. Modal and median values are shown along PC1 and PC2; TPS-grids indicate changes

862 in modal value between time-bins.

863 FIG. 9. Regional morphospace time-series. (A-B) Jittered box-plots visualizing the distribution of

864 time-bins along PC1 and PC2 ( $n=153)$. TPS-grids correspond to modal values within each time-bin.

865 FIG. 10. Superorder-level clade morphospace using the global four-age time-binning scheme.

866 (A-D) Frequency histogram plots for PC1-PC2. Measures of tendency, including the median (dashed

867 line) and arithmetic (solid line) mean are shown. Clade sample sizes by time-bin are indicated.

868 FIG. 11. Order-level clade morphospace using the four-age time-binning scheme. (A-B)

869 Patterns along PC1 and PC2. (C-D) Minimum and maximum values along the ordinated axes.

870 Sampling was insufficient to estimate reliable disparity for Echinorhiniformes. Measures of tendency,

871 including the median and arithmetic mean are shown with computed 95\% non-parametric bootstrap

872 confidence intervals and potential outliers. 
bioRxiv preprint doi: https://doi org/10.1101/2021.01.20.427414; this version posted January 20,2021 . The copyright holder for this preprint (which was not certified by peer review) is the author/funder, who has granted bioRxiv a license to display the preprint in perpetuity. It is made available under aCC-BY 4.0 International license.

874 Table 1. Non-parametric analysis of variance based on a randomized residual permutation procedure

875 (RRPP) for $n=1239$. Coefficient estimation via ordinary least squares (OLS). Type I (sequential) sums of

876 squares were used to calculate the sums of squares and cross-products matrices. Effect sizes (Z) are based on the

877 F distribution.

\begin{tabular}{|c|c|c|c|c|c|c|c|}
\hline & d.f. & $\mathrm{SS}$ & MS & $\mathrm{R}^{2}$ & $\mathrm{~F}$ & $\mathrm{Z}$ & $\operatorname{Pr}(>F)$ \\
\hline \multicolumn{8}{|l|}{ All PC-axes } \\
\hline$\sim$ groups (clades) & 8 & 18.744 & 2.34294 & 0.18931 & 35.904 & 10.892 & $0.001 * *$ \\
\hline \multicolumn{8}{|l|}{ PC1 } \\
\hline$\sim$ groups (clades) & 8 & 13.737 & 1.71707 & 0.22474 & 44.569 & 7.3642 & $0.001 * *$ \\
\hline \multicolumn{8}{|l|}{ PC2 } \\
\hline$\sim$ groups (clades) & 8 & 1.4895 & 0.186190 & 0.12352 & 21.668 & 5.8106 & $0.001 * *$ \\
\hline \multicolumn{8}{|l|}{ PC3 } \\
\hline$\sim$ groups (clades) & 8 & 2.1710 & 0.271372 & 0.20412 & 39.431 & 7.0403 & $0.001 * *$ \\
\hline \multicolumn{8}{|l|}{ PC4 } \\
\hline$\sim$ groups (clades) & 8 & 0.3986 & 0.049819 & 0.08708 & 14.665 & 5.1632 & $0.001 * *$ \\
\hline
\end{tabular}

878 Symbols: $d . f$. = degrees of freedom; SS = sequential sums of squares; $\mathrm{MS}=$ Mean squares; $\mathrm{F}$ statistics = F value

879 by permutation; $\mathrm{R}^{2}=$ coefficient of determination; $\mathrm{Z}=$ effect size. $P$-values are based on 999 permutations. 
bioRxiv preprint doi: https://doi org/10.1101/2021.01.20,427414; this version posted January 20,2021 . The copyright holder for this preprint (which was not certified by peer review) is the author/funder, who has granted bioRxiv a license to display the preprint in perpetuity. It is made available under aCC-BY 4.0 International license.

Table 2. Non-parametric analysis of variance based on RRPP for all PCs. Coefficient estimation via ordinary least squares (OLS). Type I (sequential) sums of squares were used to calculate sums of squares and cross-products matrices. Effect sizes (Z) based on F distribution.

\begin{tabular}{|c|c|c|c|c|c|c|c|}
\hline & $d . f$. & SS & MS & $\mathrm{R}^{2}$ & $\mathrm{~F}$ & $\mathrm{Z}$ & $\operatorname{Pr}(>F)$ \\
\hline \multicolumn{8}{|l|}{ Selachimorpha } \\
\hline$\sim$ interaction (global 5-bin) & 4 & 2.625 & 0.65621 & 0.02911 & 8.6269 & 5.0104 & $0.001 * *$ \\
\hline$\sim$ interaction (global 4-bin) & 3 & 2.219 & 0.73957 & 0.0234 & 9.5354 & 4.9451 & $0.001 * *$ \\
\hline$\sim$ interaction (regional 3-bin) & 2 & 0.840 & 0.41999 & 0.06043 & 4.8235 & 2.8145 & $0.002 * *$ \\
\hline \multicolumn{8}{|c|}{$\begin{array}{l}\text { Galeomorphii } \\
\text { (Synechodontiformes included) }\end{array}$} \\
\hline$\sim$ interaction (global 4-bin) & 3 & 2.254 & 0.75136 & 0.02966 & 10.587 & 5.0617 & $0.001 * *$ \\
\hline$\sim$ interaction (regional 3-bin) & 2 & 0.7811 & 0.39053 & 0.07727 & 4.7316 & 2.796 & $0.003 * *$ \\
\hline \multicolumn{8}{|l|}{ Squalomorphii } \\
\hline$\sim$ interaction (global 4-bin) & 3 & 0.9088 & 0.302947 & 0.07875 & 4.3028 & 3.8612 & $0.001 * *$ \\
\hline$\sim$ interaction (regional 3-bin) & 2 & 0.30381 & 0.151907 & 0.12846 & 2.5058 & 1.9687 & $0.015^{*}$ \\
\hline
\end{tabular}

884 by permutation; $\mathrm{R}^{2}=$ coefficient of determination; $\mathrm{Z}=$ effect size. $P$-values are based on 999 permutations. 
A

2D Tooth Shape Morphospace

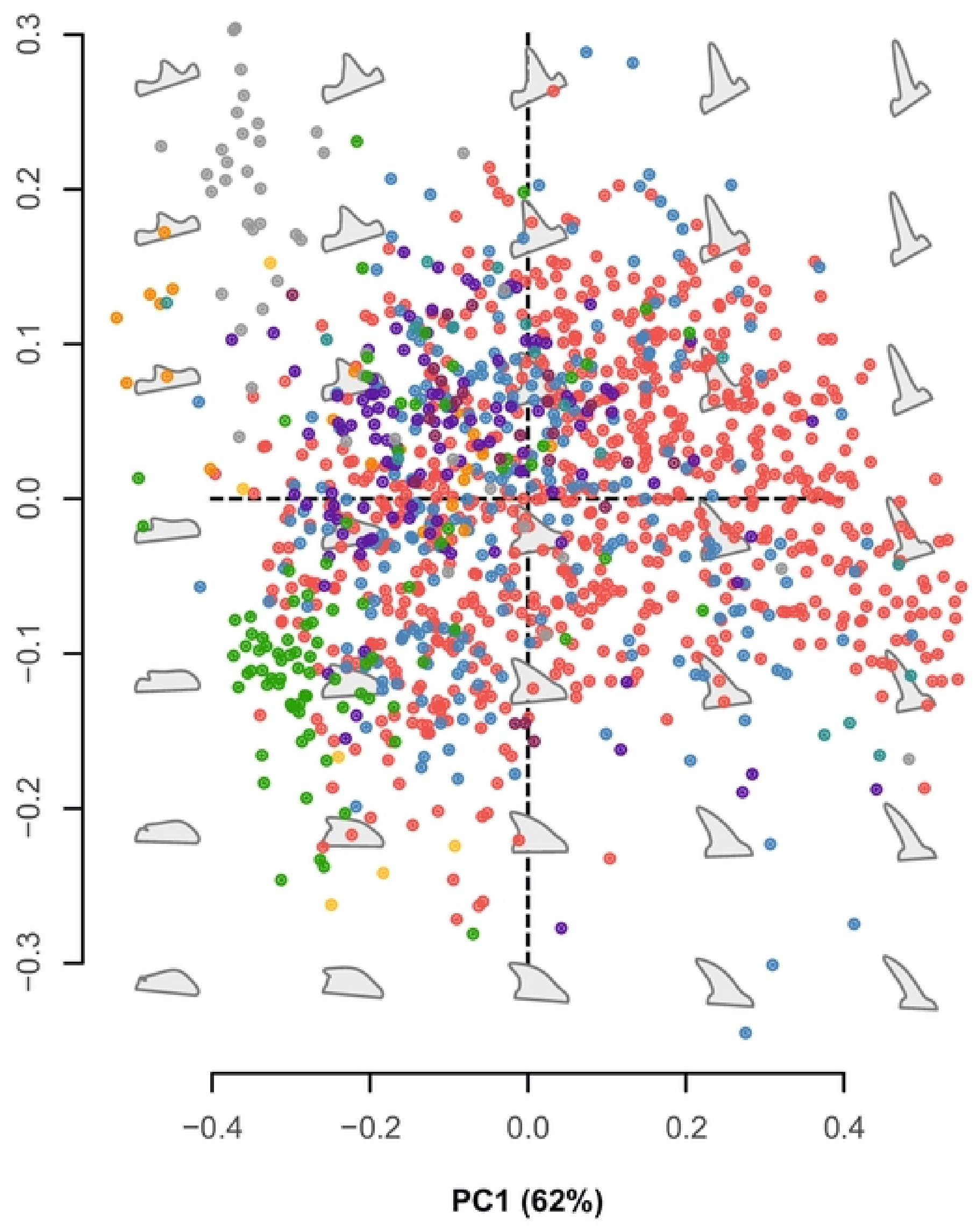

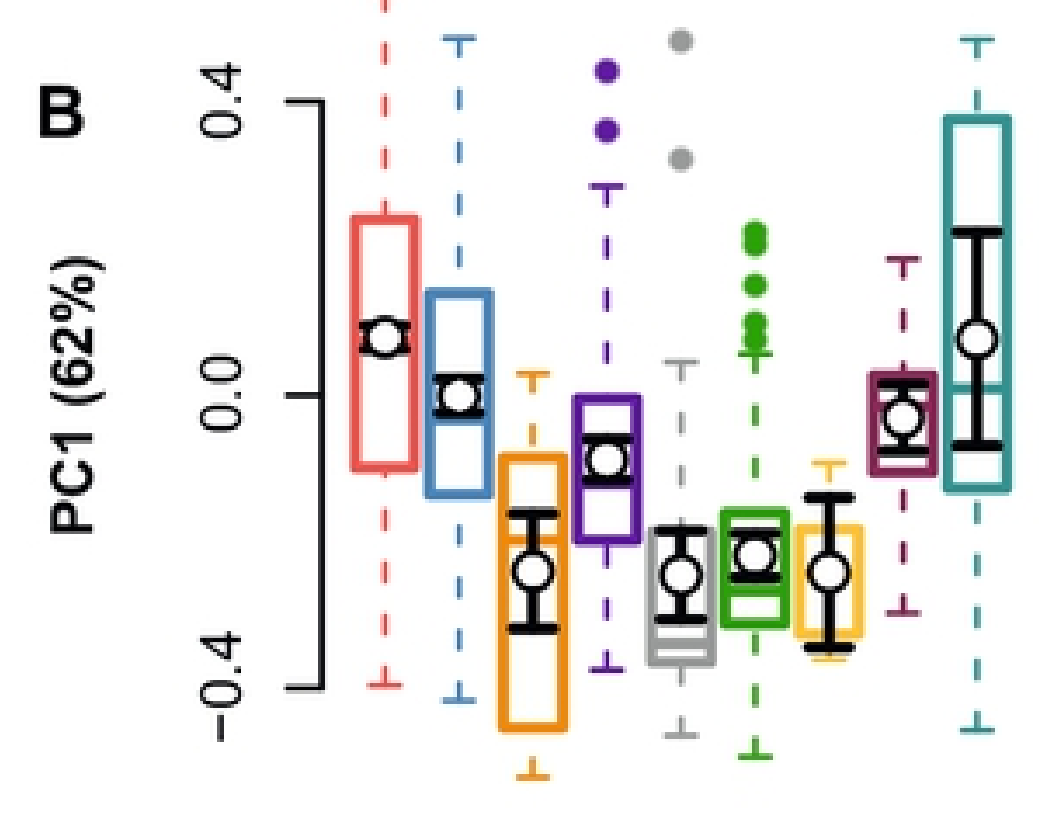

\section{Orders}

Sample size (N)

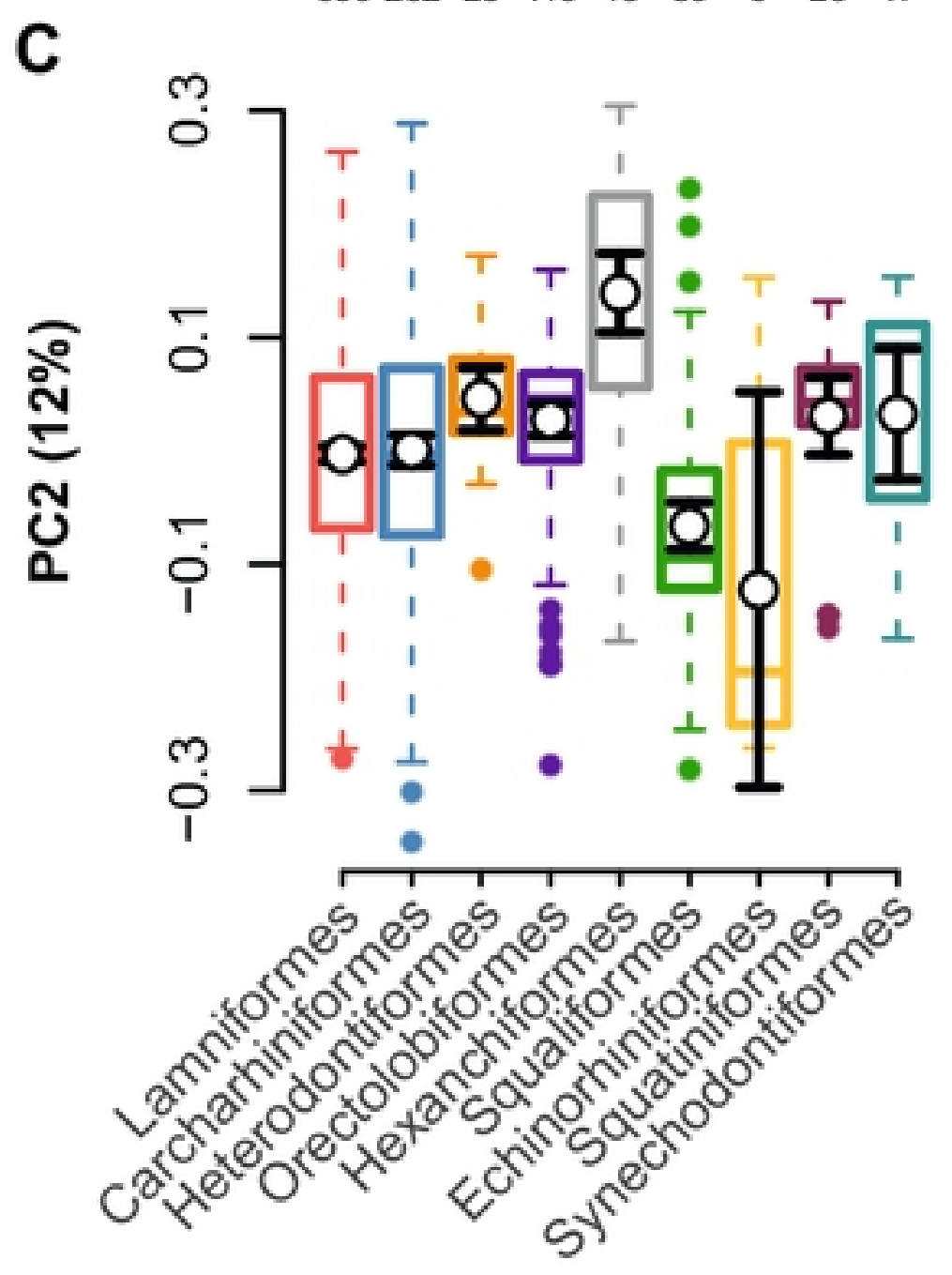

Figure 


\section{Deformation isolines using Thin Plate Splines}

Principal component 1 (62\%)

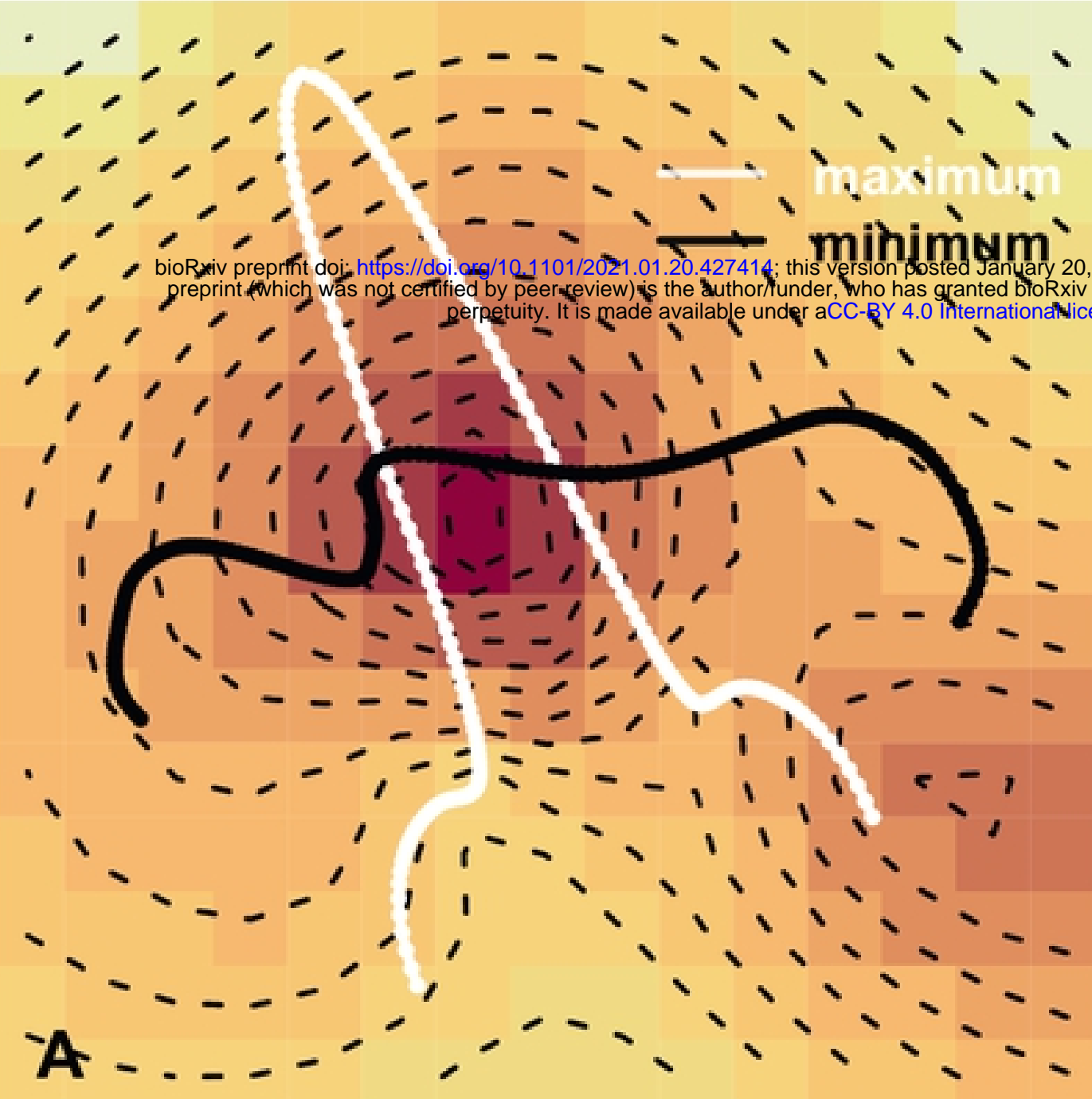

Principal component 3 (11\%)

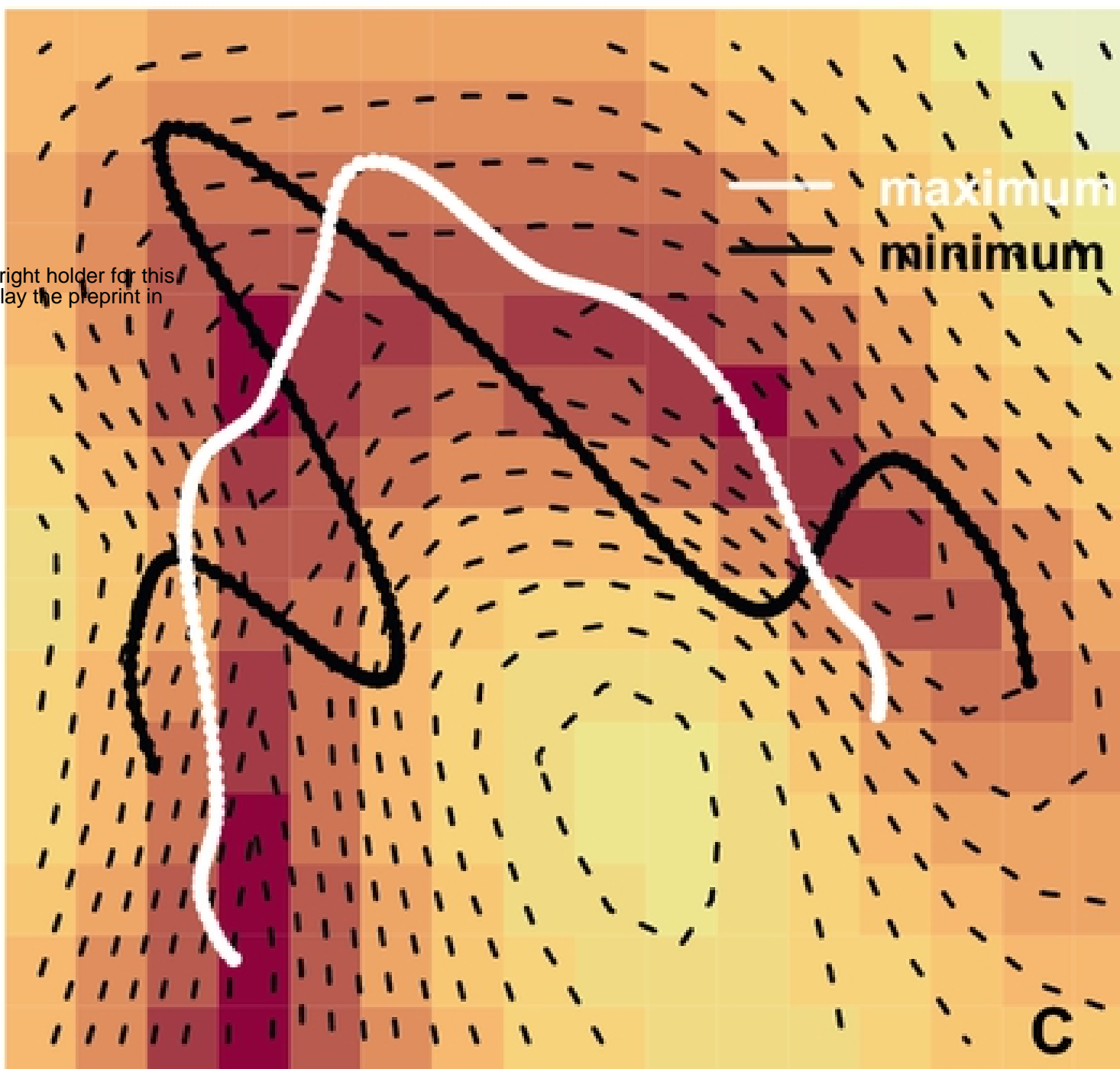

Principal component 2 (12\%)

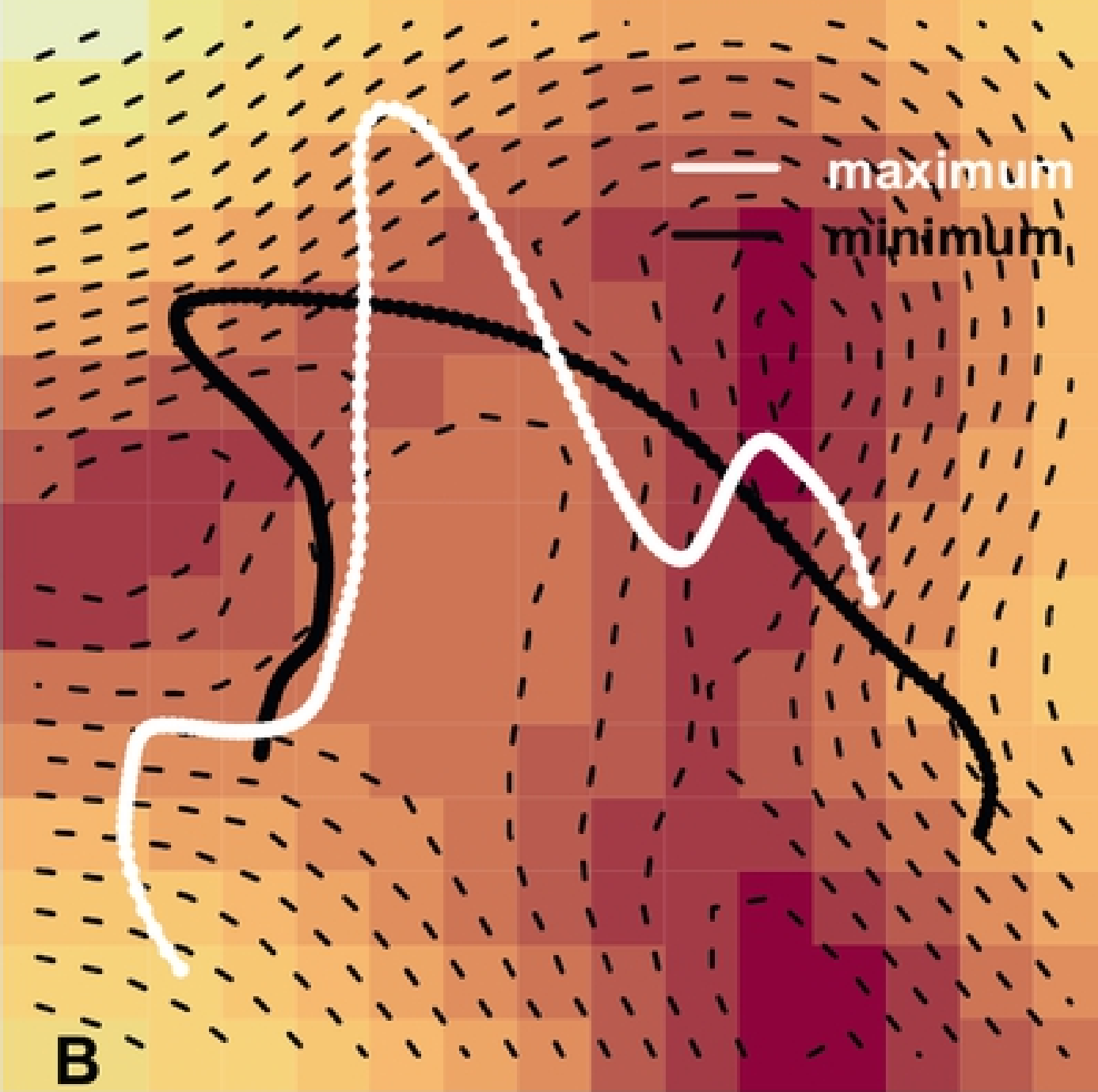

Principal component 4 (5\%)

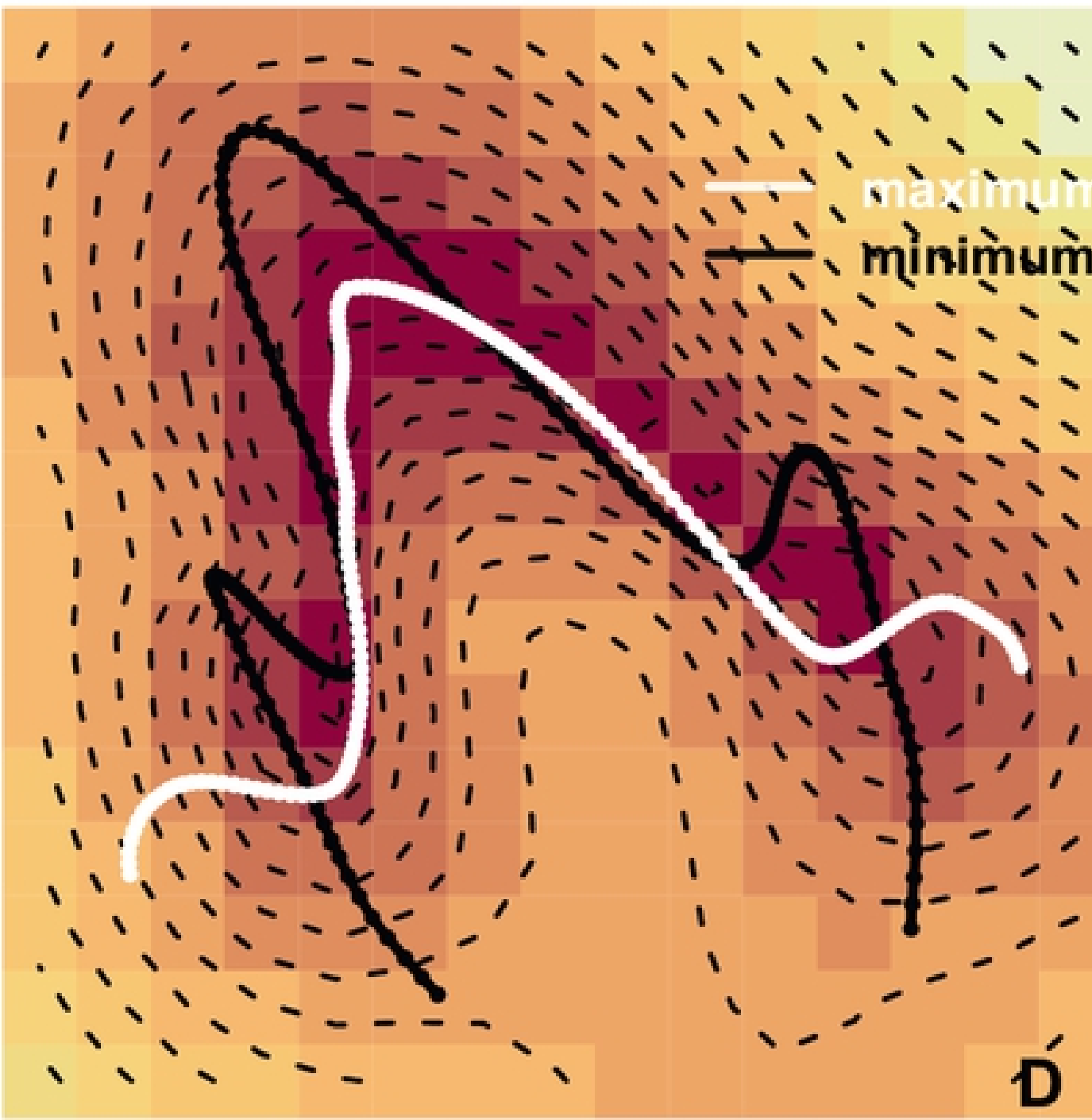

Figure 
Shark dental disparity and generic richness

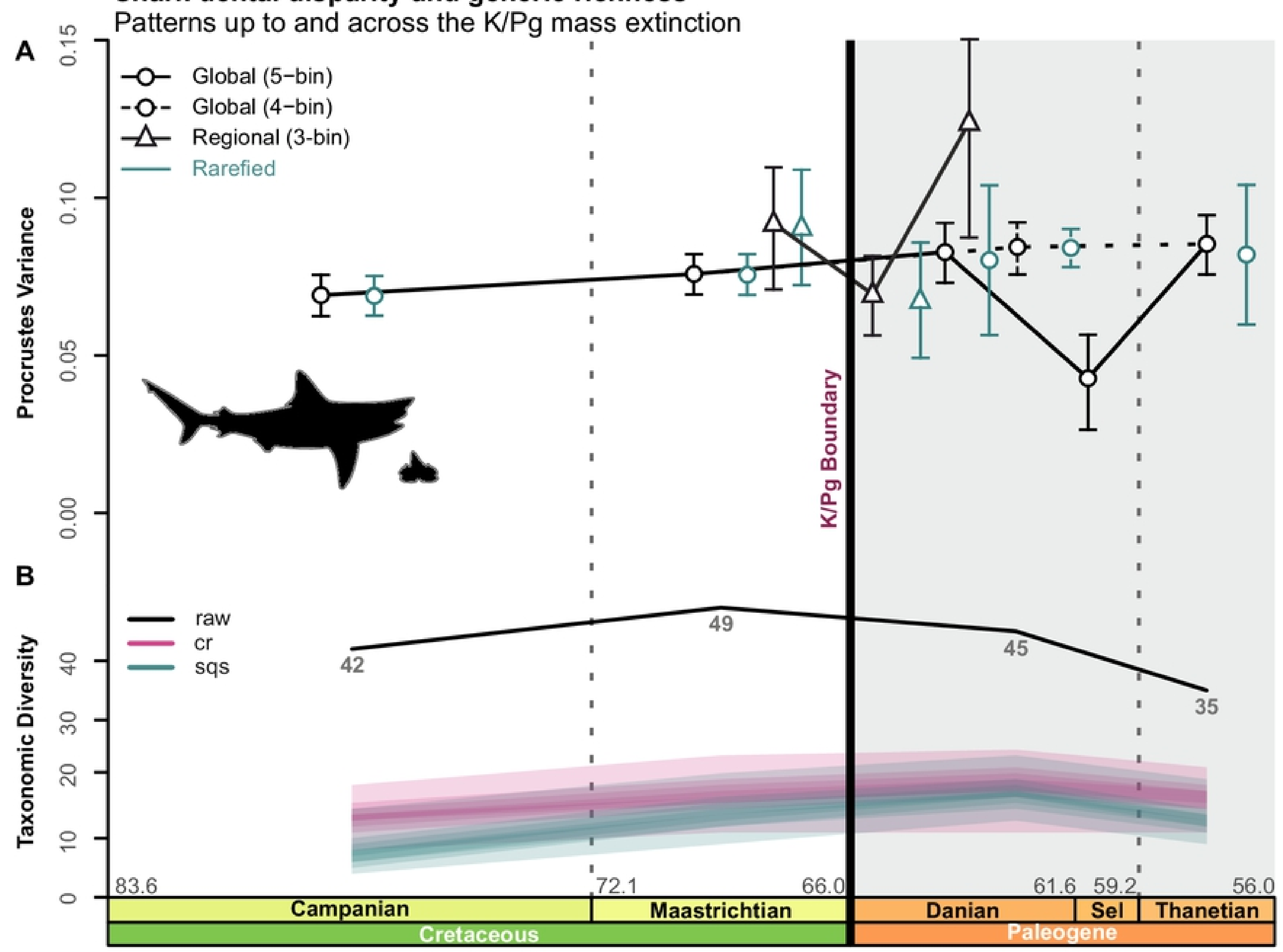

Time (Ma)

Figure 


\section{Dental disparity of shark superorders}

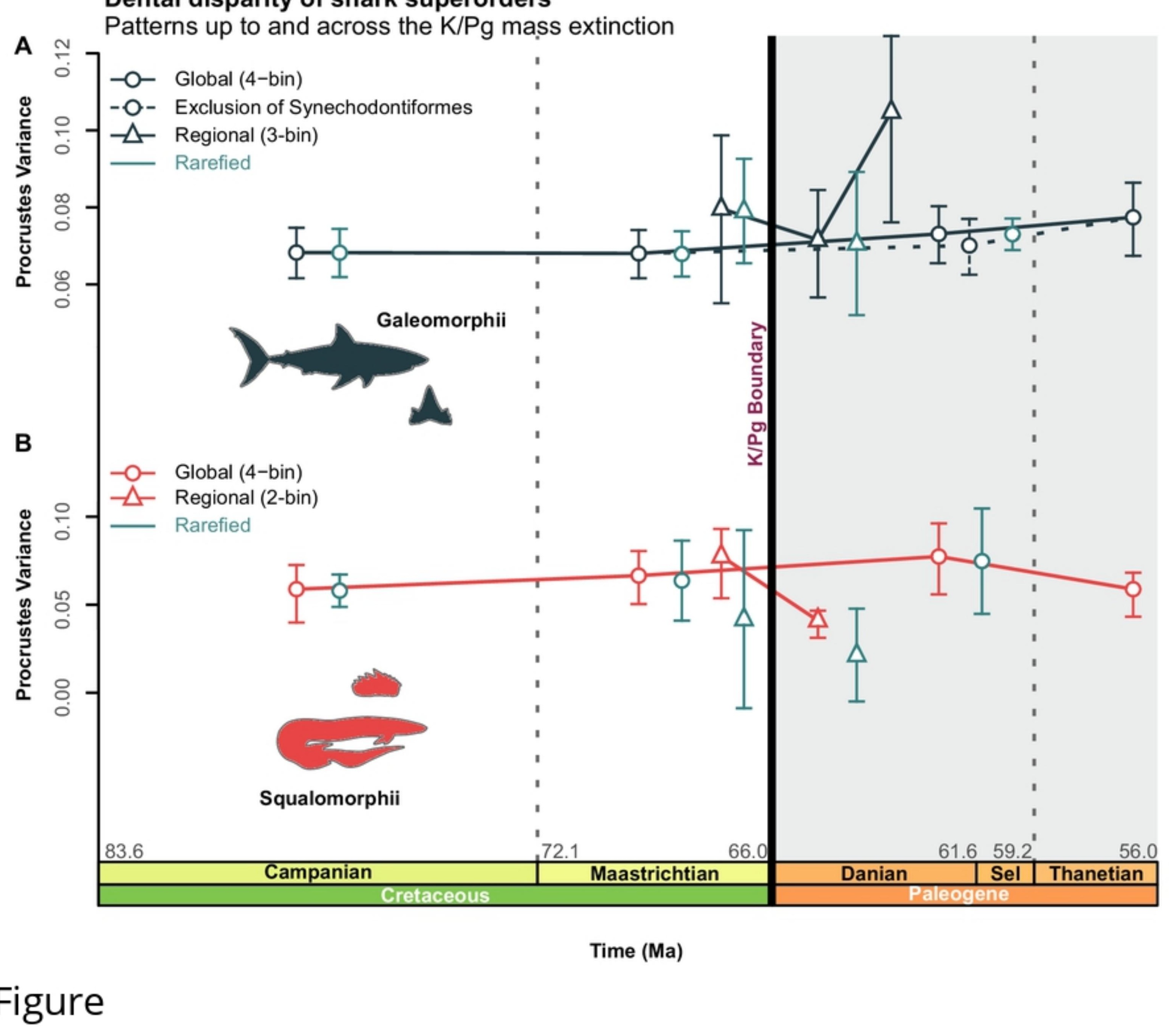




\section{Temporal Resolution}

-0 - Global-scale $-\Delta \leftarrow$ Regional-scale

$\mathrm{K} / \mathrm{Pg}$ Boundary
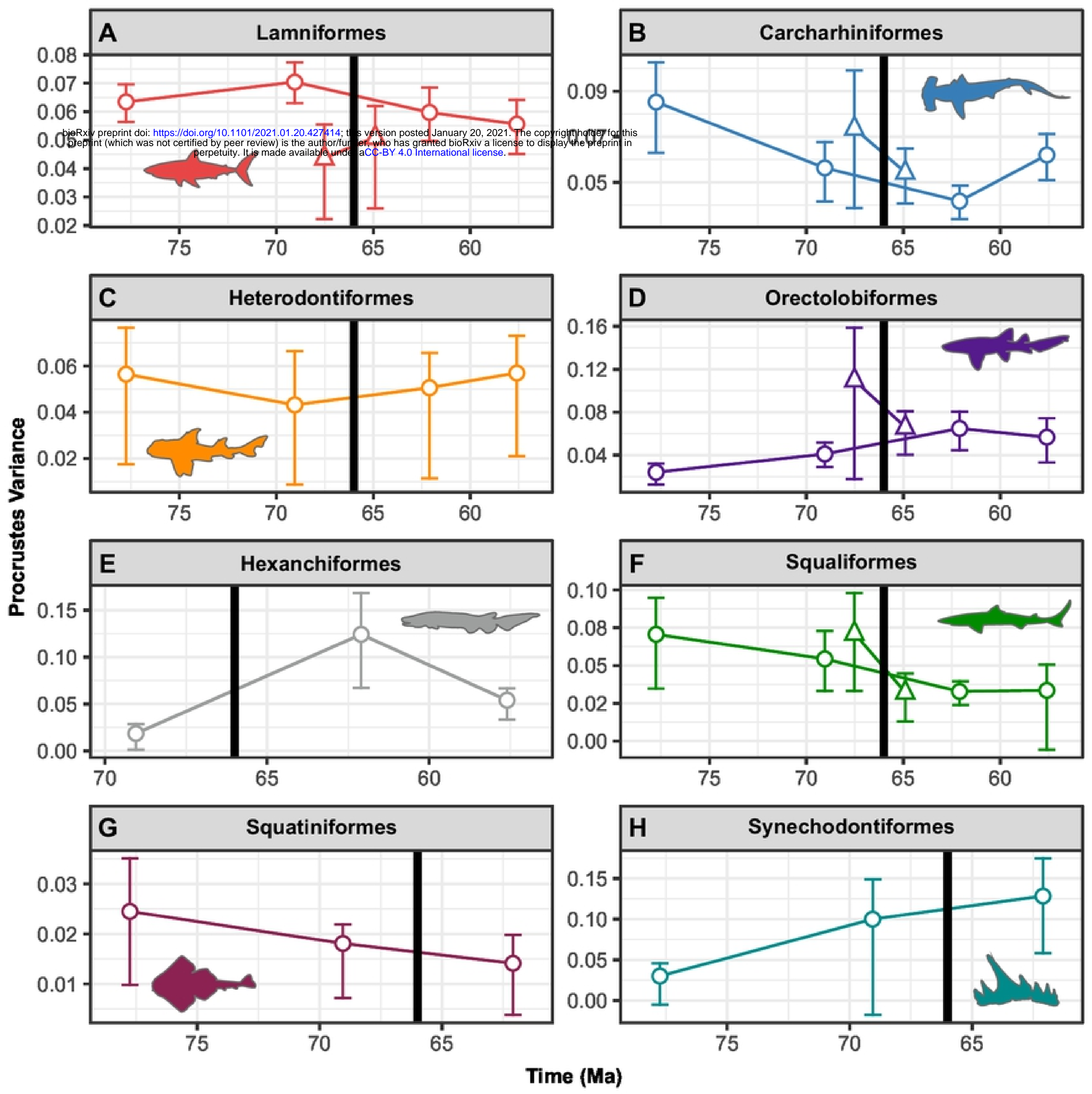

Figure 

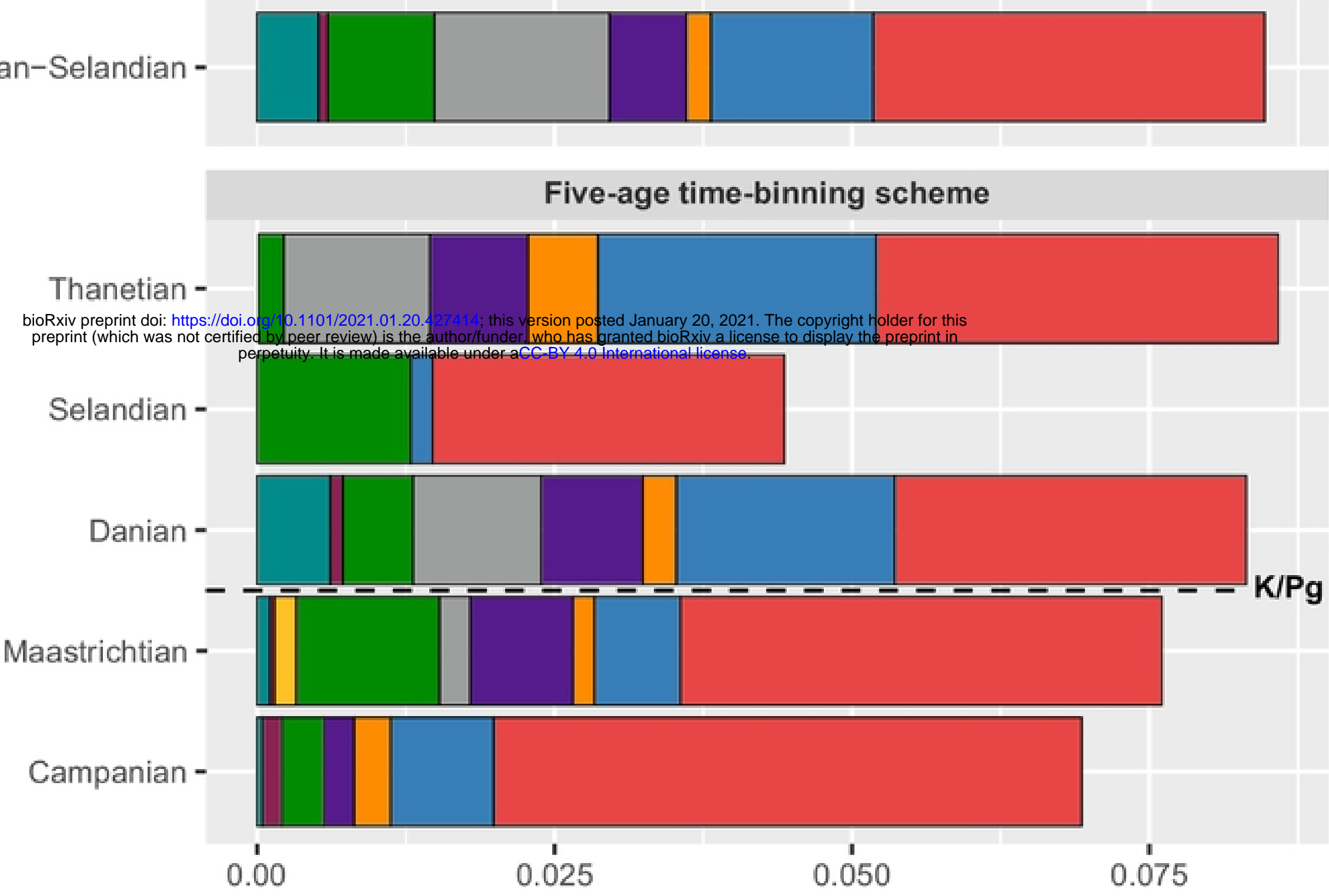

Procrustes Variance

B
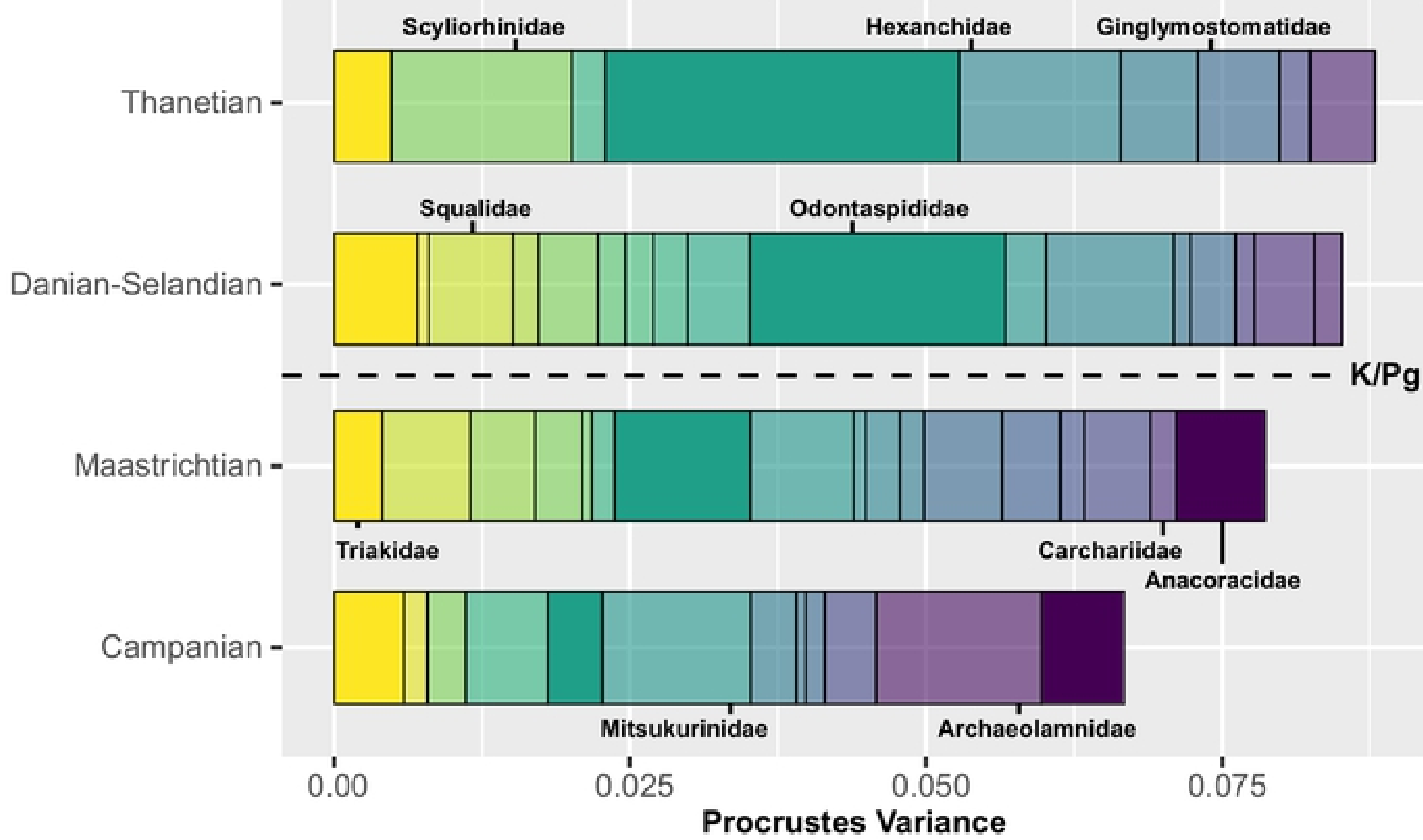

\section{Orders}

Lamniformes Carcharhiniformes Heterodontiformes Orectolobiformes

Hexanchiformes Squaliformes Echinorhiniformes Squatiniformes Synechodontiformes

\section{Family}

Anacoracidae Archaeolamnidae Carcharhinidae Carchariidae Centrophoridae Cretoxyrhinidae Echinorhinidae Etmopteridae Ginglymostomatidae - Hemiscyllidae Heterodontidae Hexanchidae Isuridae Mitsukurinidae Odontaspididae Orthacodontidae Otodontidae Palaeospinacidae Parascyllidae Pseudocoracidae Scyliorhinidae - Serratolamnidae Somniosidae Squalidae Squatinidae Triakidae

\section{Figure}




\section{Morphospace through time}

A $\stackrel{\circ}{\circ}$

용

?ே

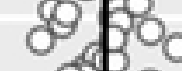

doi: hit s:ydoi.org 10.1101/2021.01 20.427414 th
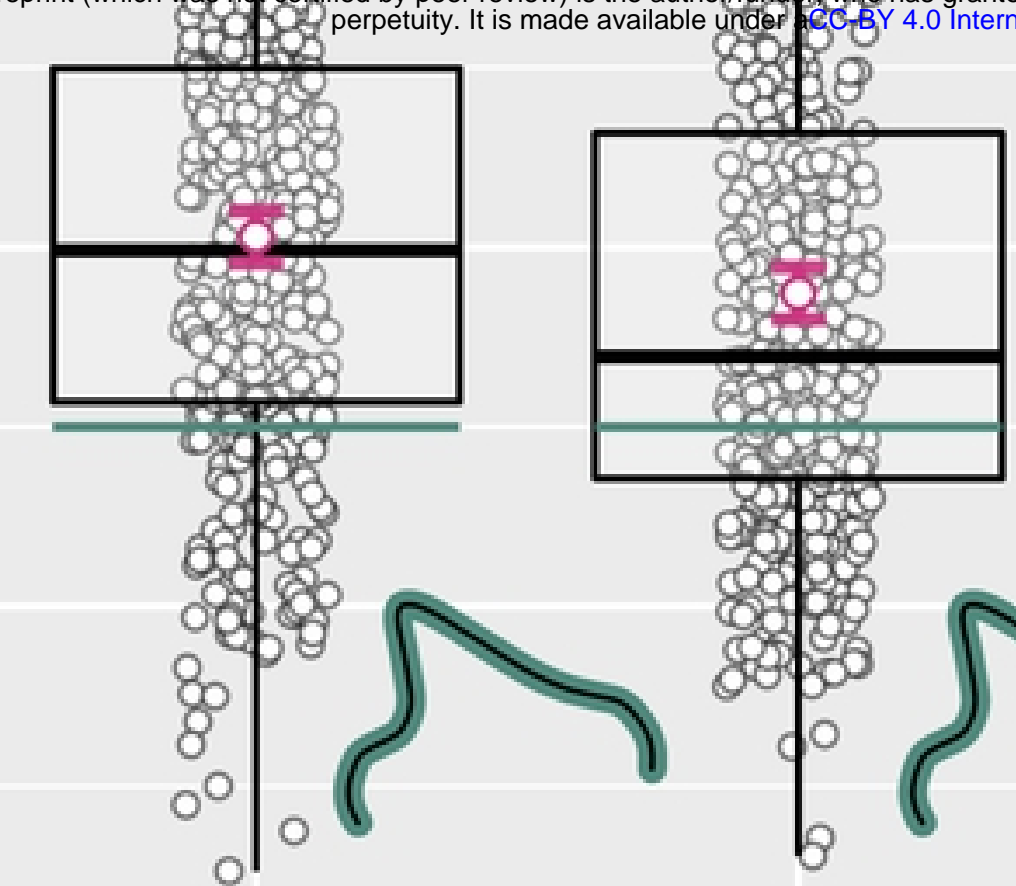

co
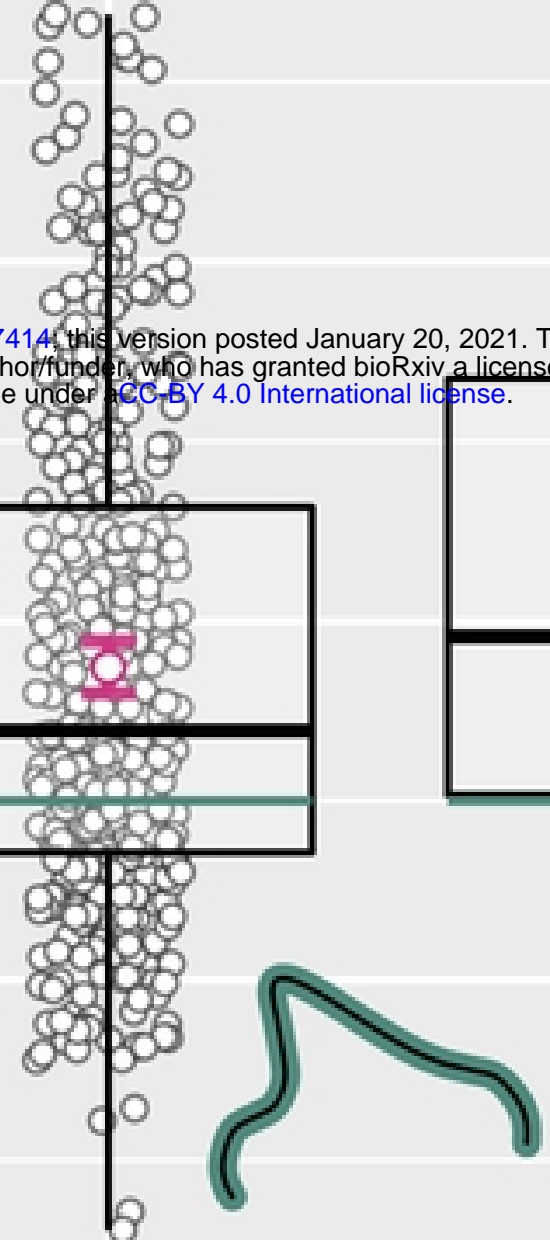

$\circ$

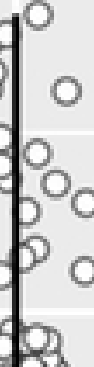

soto
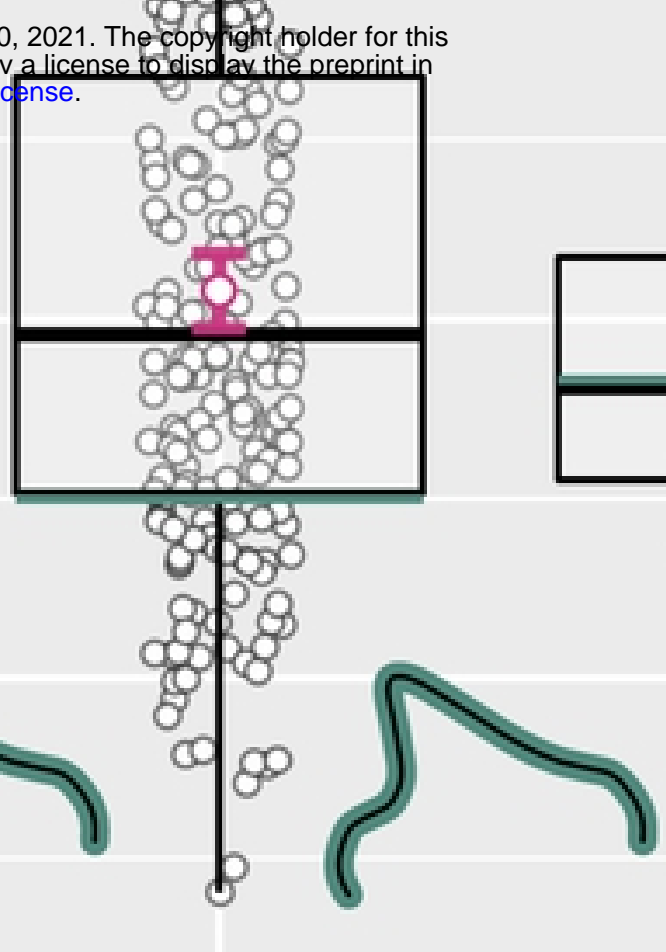

B

กิ

$-\mathrm{O}-95 \% \mathrm{Cl} \longrightarrow$ Median - Mode
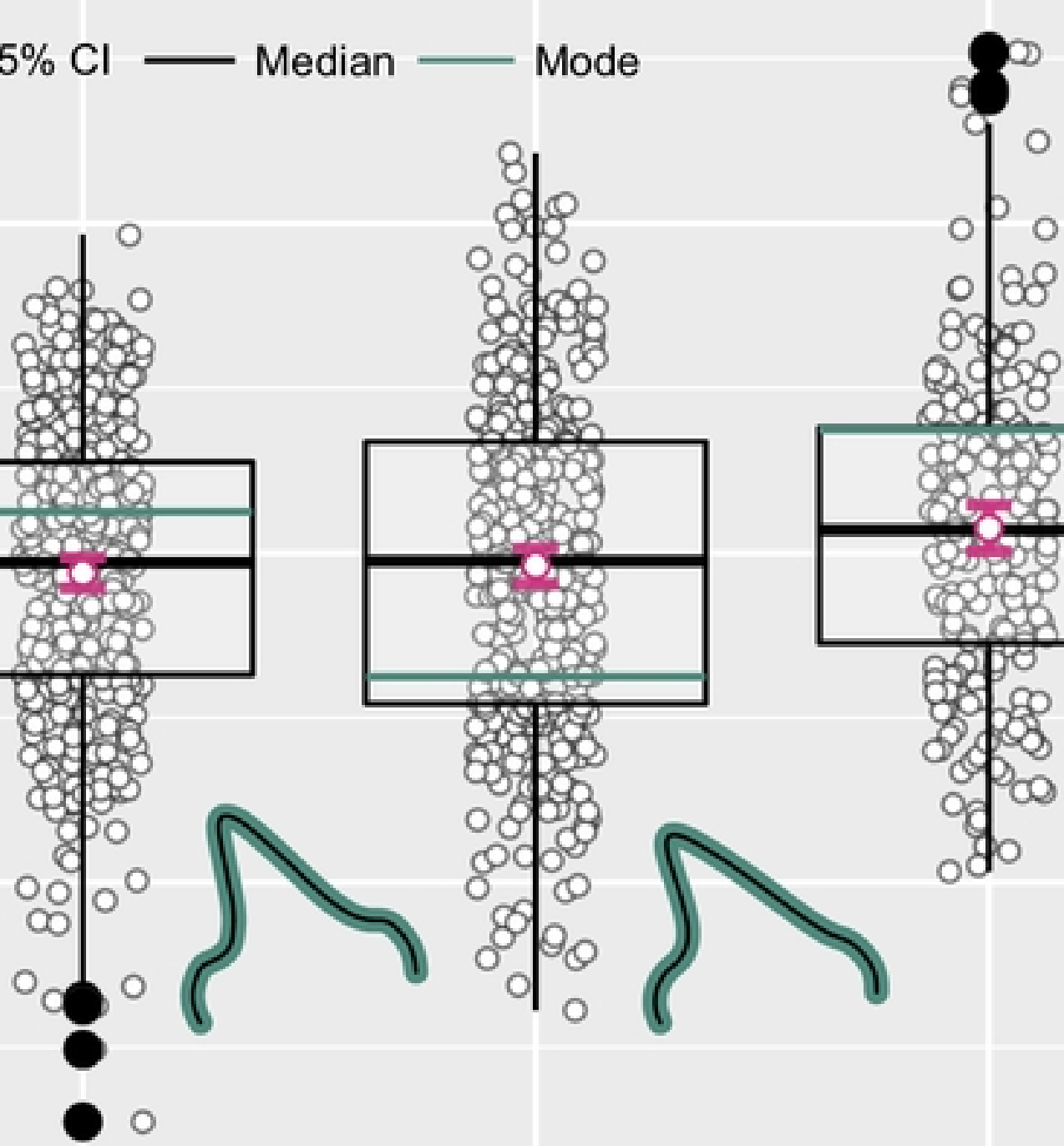

890

$8 \theta^{\circ}$
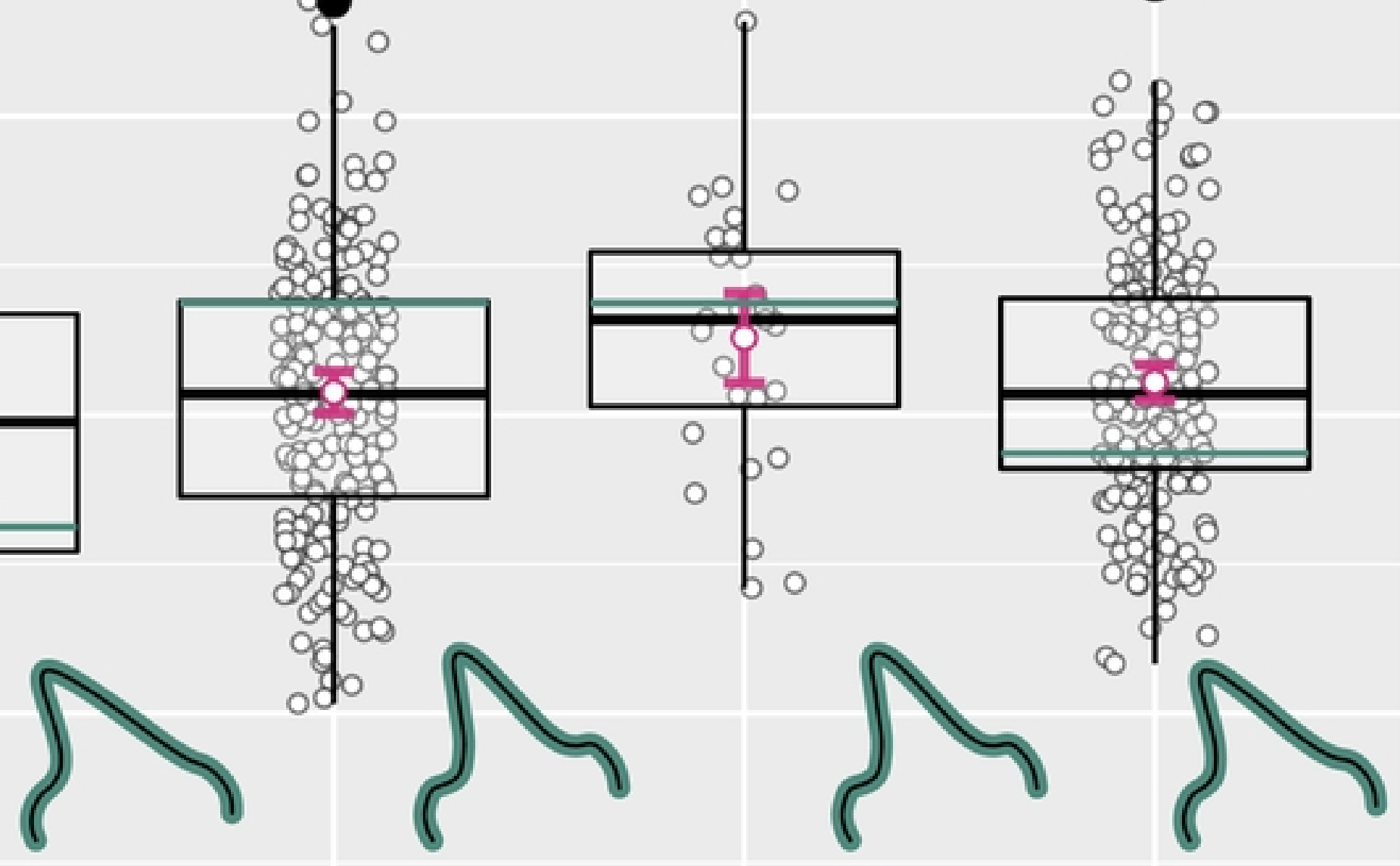

\section{Campanian}

\section{Cretaceous}

83.6

72.1

Maastrichtian

Danian

66.0

Time (Ma) 


\section{Morphospace through time}

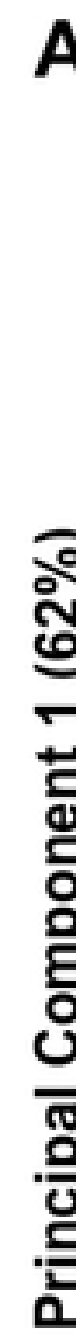

bipRxiv preprint doi:
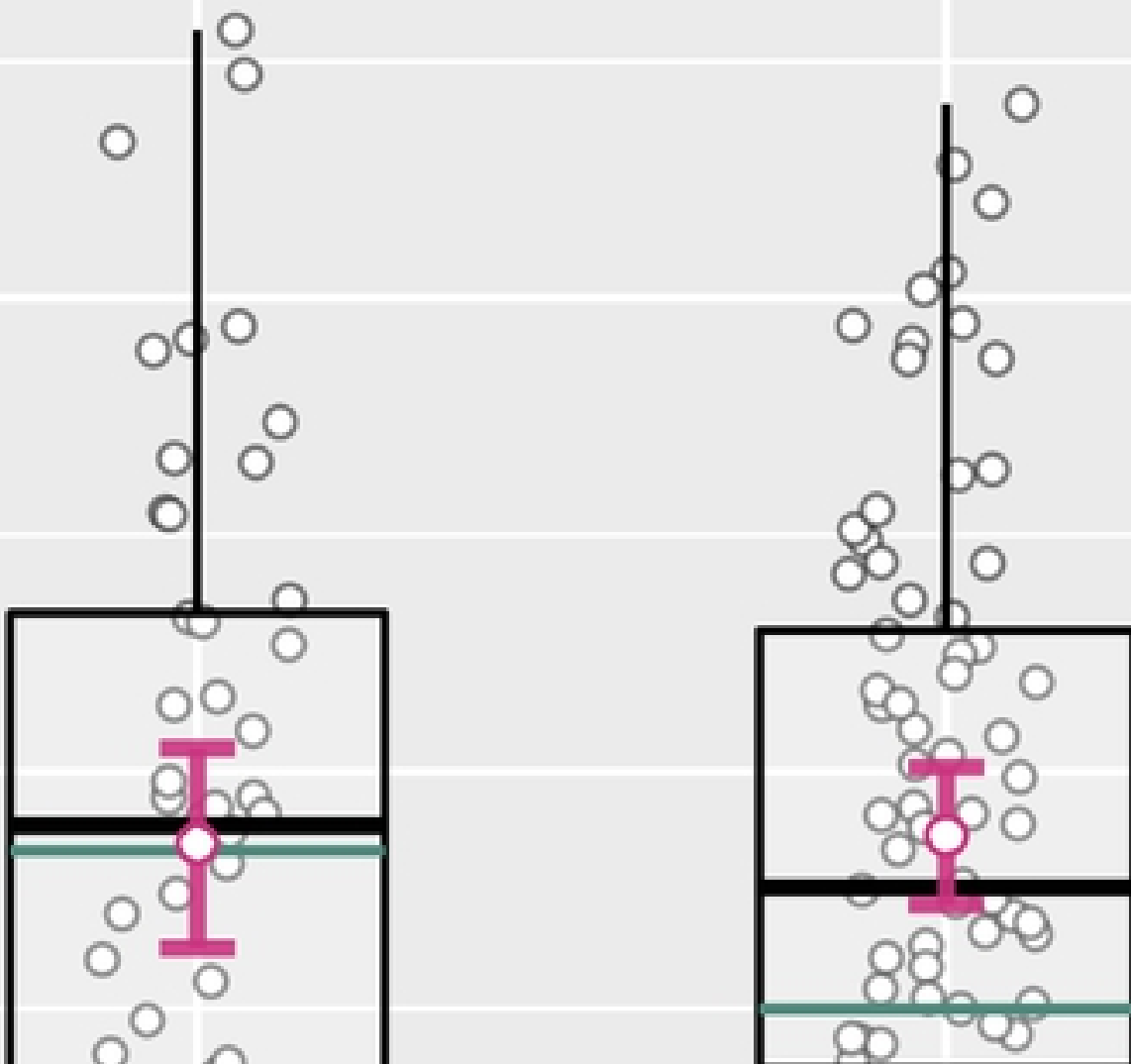

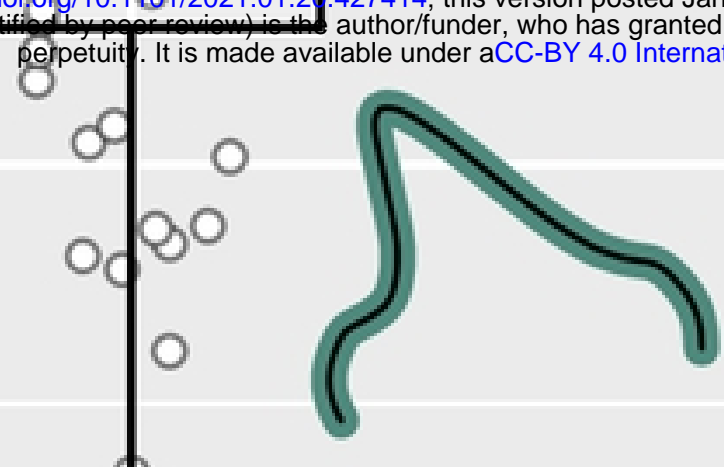

icengen

$\infty_{0}$
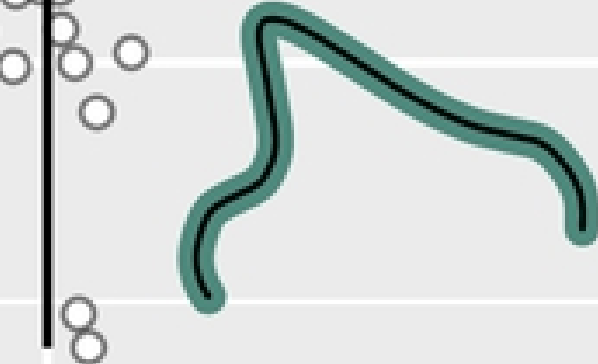

$\infty_{0}^{\infty}$

o

0

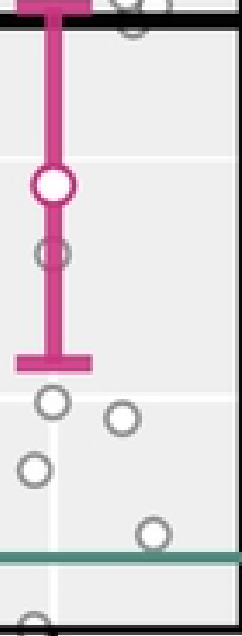

$\circ p_{0}$

o

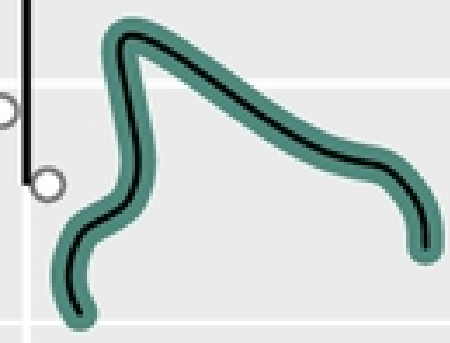

B

을

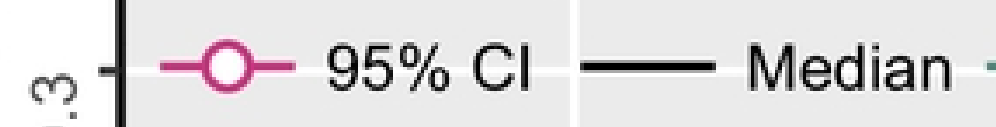

Mode
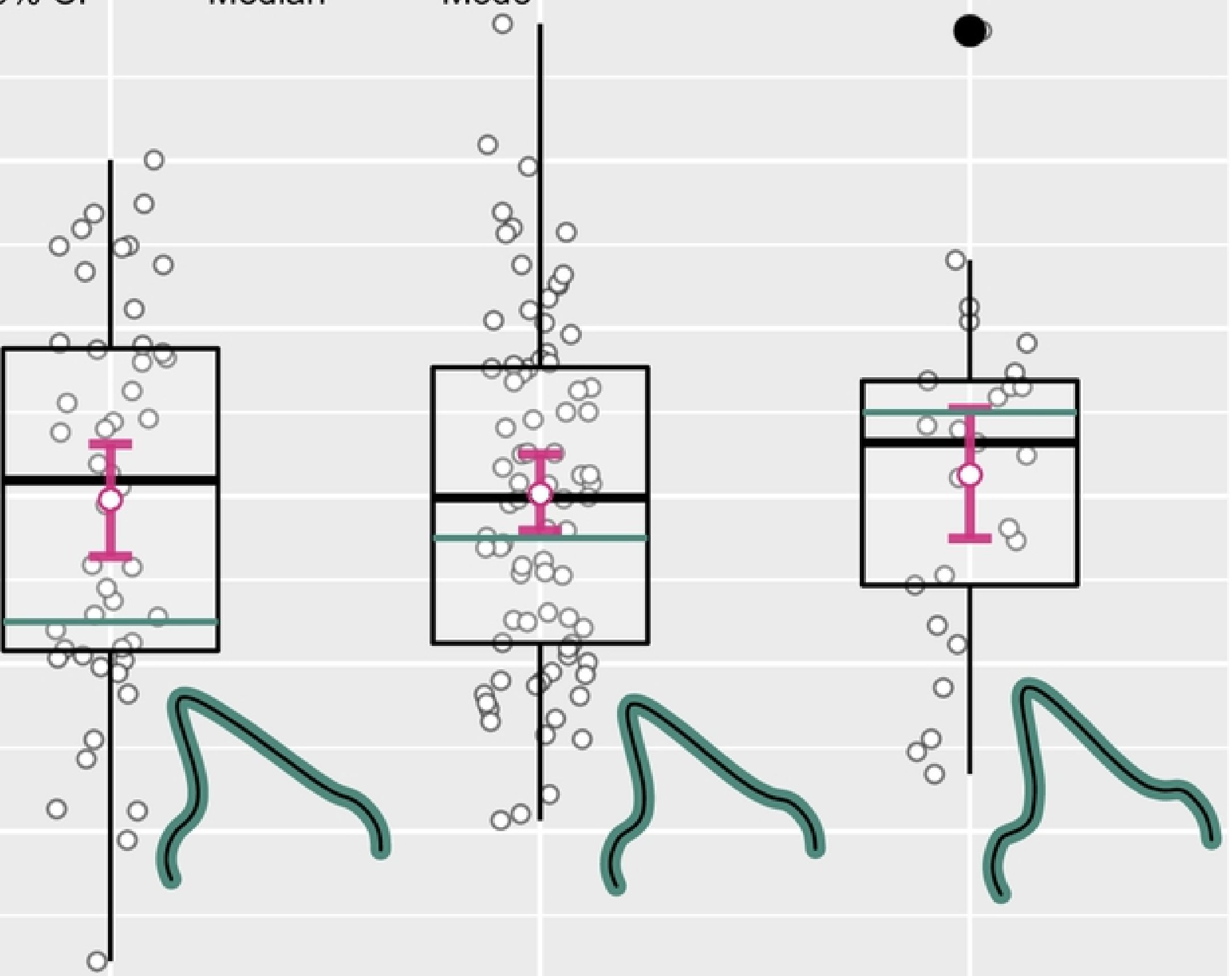

?.

Figure 


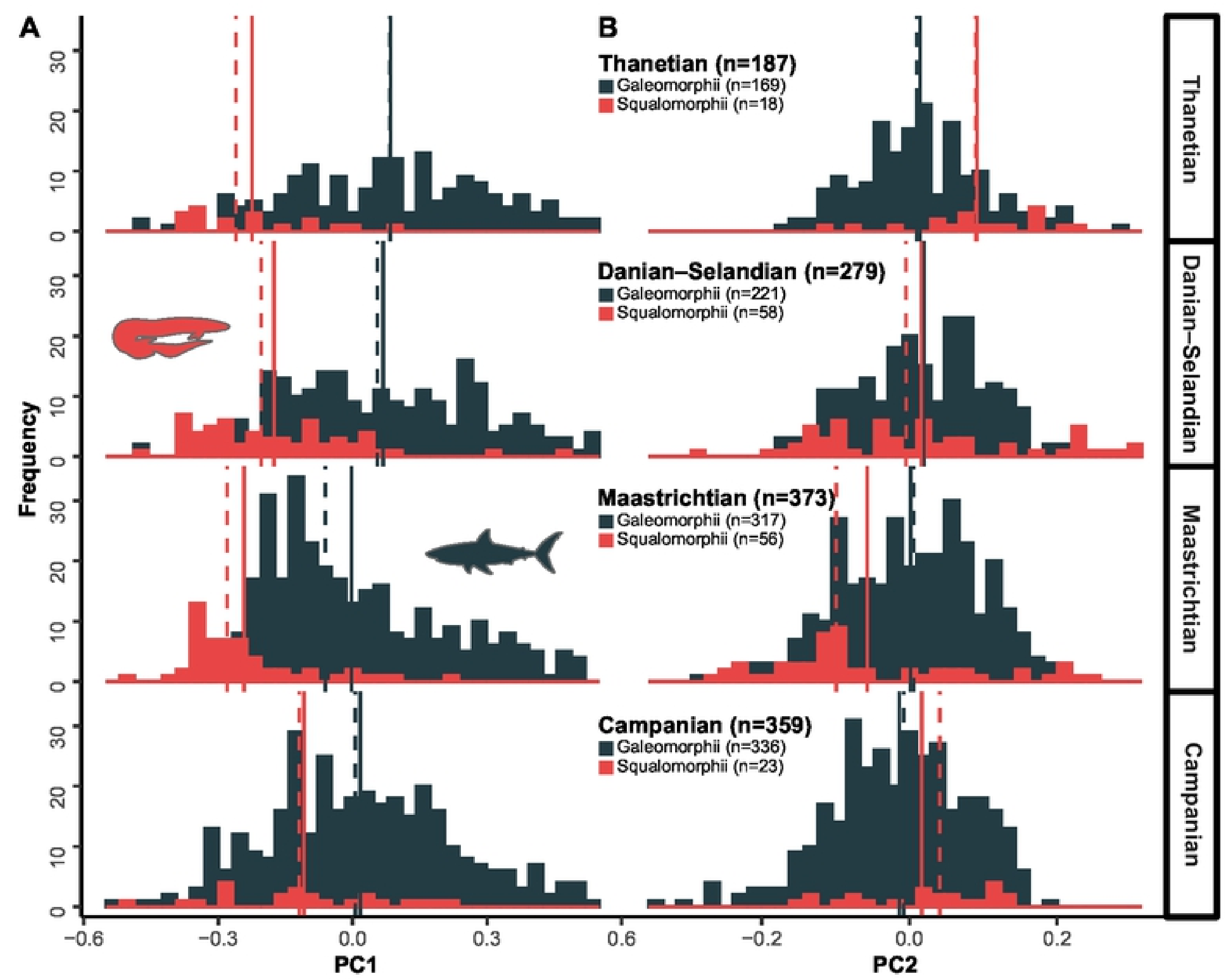

Figure 


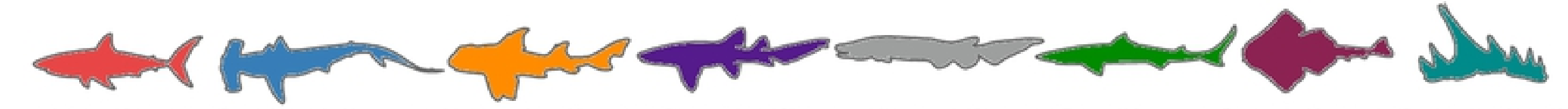

Lamniformes Carcharhiniformes Heterodontiformes Orectolobiformes Hexanchiformes Squaliformes Squatiniformes Synechodontiformes

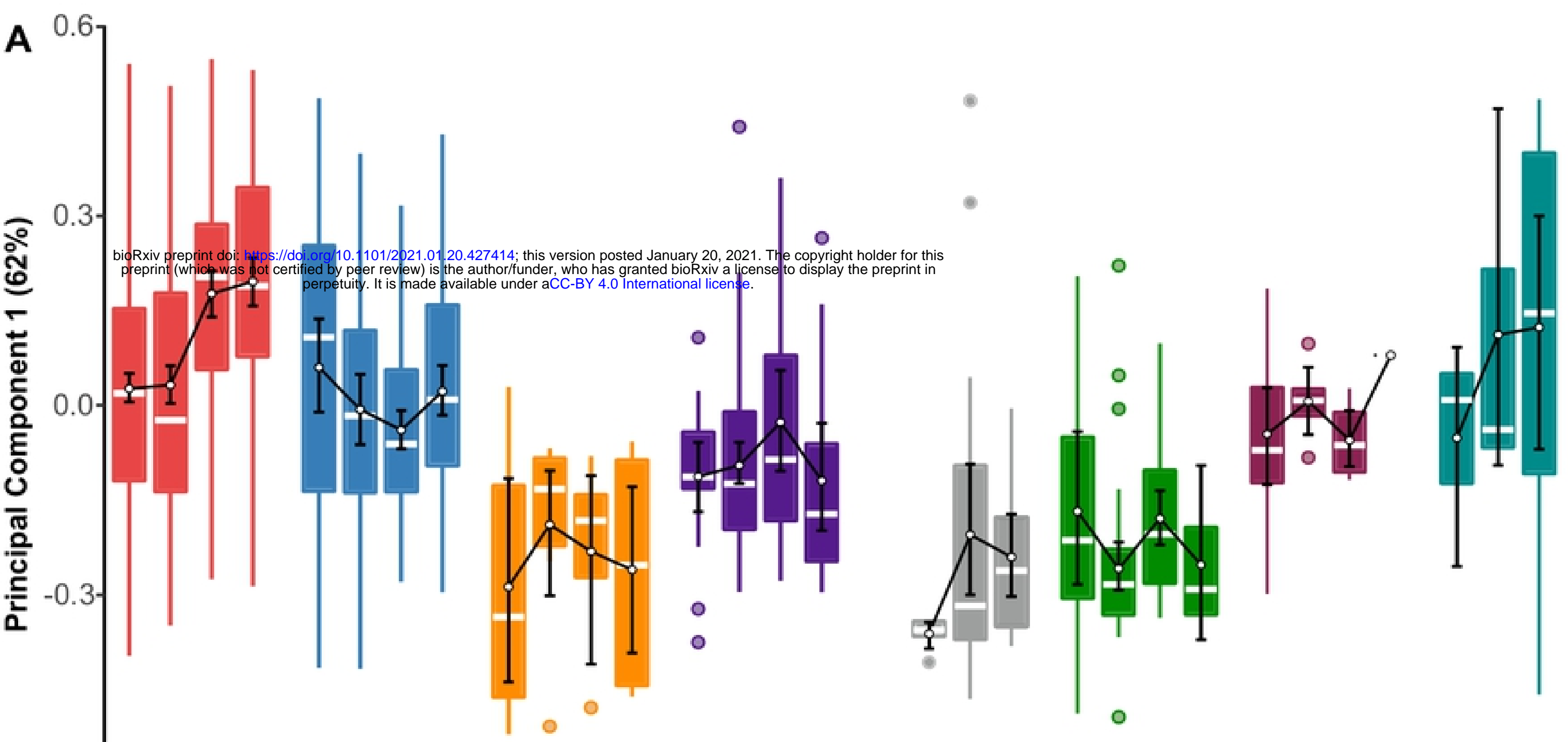

B
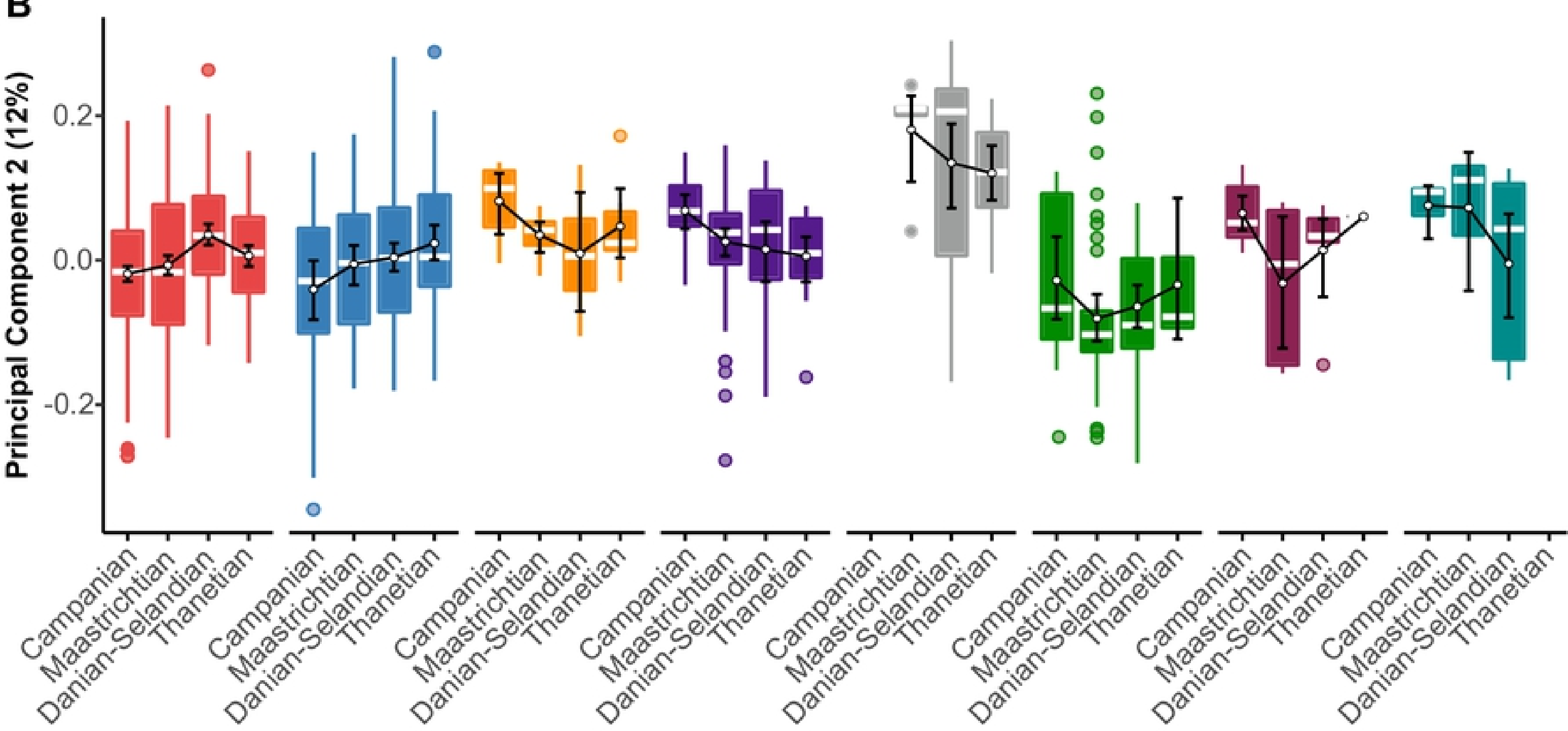

Time (Ma)

Figure 